\title{
Sustainable urban interventions in the rain forest: the experience of the city of Manaus in Brazil
}

\author{
Ana Carolina Correa de Medeiros ${ }^{1}\left[\right.$ [D $\cdot$ Roger Pamponet da Fonseca $^{1}$ (i) $\cdot$ Elizangela Francisca Sena Araújo de Silva ${ }^{1}$ (i)
}

Received: 30 September 2019 / Accepted: 24 March 2020 / Published online: 1 April 2020

(c) Springer Nature Switzerland AG 2020

\begin{abstract}
The historical downtown areas are places where once there was active urban life; however, nowadays the downtown areas are busy zones by day and empty dangerous spaces by night. It is crucial to study urban centralities to understand how to make cities more sustainable; it is vital to occupy areas already endowed with consolidated urban infrastructure rather than expand cities to suburban areas. The case of Downtown Manaus is quite similar to other cities, mainly because it has been systematically vacant, as research has shown. The main objective of this project is to reclaim this area for housing plus other mixed occupation, such as commercial, leisure and housing uses. The research methodology approach was theoretical-conceptual and empirical. As a result, the survey of vacant lots aimed identify each of the lot conditions and qualities. The investigation showed that many lots have a special appealing for housing. The proposal of small residential areas using the Pod Houses and a mixed-use approach, where residents can also use the space for commercial exploration, suits the focus on multiplicity within a city. Finally, on the public realm, repossession tactics focused on parks, bridges and parking lots aiming to recover degraded areas.
\end{abstract}

Keywords Historical downtown areas · Sustainable urban planning · Sustainable housing · Terrain vagues · Manaus

\section{Introduction}

Why do the population rate of many historical downtown have been dropping? This is the main question surrounding this research. The goal of this work is to understand the vacancy of historical downtown areas and to propose sustainable solutions for this problem. To address this problem, the sample selected was Manaus, capital of Amazonas state, in Brazil. That is the reason why this paper is a result of a case study of Manaus reality, even if the conclusions of this research are general than the original intention.

The importance of this work is because Manaus is a city within the world's largest rain forest, the Amazon biome. The Amazon appears as a focus of many discussions, especially after the recent fires on 2019. In a city that emerges from the forest, it is important to think on sustainable urban planning solutions that can address the urban sprawling and the relocation of inhabitants to forested areas. That is why the focus of this paper is to present solutions for Manaus historical downtown area, where there are many vacant lots and vacant spaces. Manaus' Downtown is a neighborhood that has consolidated infrastructure which is desirable for people to live.

For this paper, the research approach was theoretical-conceptual and empirical. The primary source of data were official documents, legislation and IBGE's (Brazilian

\footnotetext{
The first phase of this work received honorable mention at XXV CONIC 2016/2016, a scientific event of Federal University of Amazonas. The complete work as presented on this article received Best Paper Award at IDEAS Conference, from June 17 to 19, 2019 , a scientific event performed by Federal University of Amazonas, Linköping University and Federal University of ABC.
}

Ana Carolina Correa de Medeiros, carolmedeiros.peace@gmail.com; Roger Pamponet da Fonseca, rogerpamponet@ufam.edu.br; Elizangela Francisca Sena Araújo de Silva, efsaraujosilva@hotmail.com | ${ }^{1}$ Federal University of Amazonas, Manaus, Brazil. 
Institute of Geography and Statistics) data. After the theoretical-conceptual phase, the empirical stage of the research was the survey of vacant lots aimed identify each of the lot conditions and qualities. Only after the collection and treatment of these data, it was possible to start thinking about the proposed solutions.

There are many vacant lots within Manaus Downtown area (district name in Portuguese: Centro); therefore, the propositions main goal is to lodge lots that need a fast and seasonal occupation. It is important to notice that all vacant lots studied on this paper have obstacles that hinder their permanent occupation. With this brief foreword, it is essential to highlight that the main objective of this study is to propose the sustainable occupation of Manaus' Downtown area. The goal here is to propose sustainable solutions that can bring a diversity of uses and repopulate this neighborhood.

This paper follows a strict methodology. Therefore, each section has a specific objective. Section 2 presents the systematic review about urban centralities, presenting the definitions and concepts that ground the research. Section 3 highlights the scientific approach for this paper. Section 4 points the results of the empirical study of the vacant lots on Manaus' Downtown Area. Section 5 brings the architecture projects and urban planning, as a sustainable outcome for historical downtown areas that have similarities to Manaus' case. Finally, the conclusions, in Sect. 6, demonstrate the new challenges and the future for this kind of research.

\section{Urban centralities: theoretical background}

To answer the main question brought on the first section of this paper, it is essential to take notice of the importance of the old downtown areas in the current city development. The historical centers of the cities constitute the dominant element of a new syntax of the urban centers. Villaça [1] points that the intra-urban space (spaces within the city) emerges from the periphery-center displacement of people turning the old centers part of a merchandise that is an input for basic production.

In addition, Villaça introduce the concept of "main center." At first glance, it seems a technical redundancy to call a space a "main center," since the center is a key urban area, due to its functions and its status. However, there are several other urban centers and subcenters within a city network [1]. The example of Chilean's Santiago shows that some older downtown does get depopulated and can lose residential vocation in relation to other more profitable land uses, such as commerce and offices [2]. This phenomenon is not different from what other Latin American cities experience, such as the examples of Mexico City, Quito or even, Salvador, in Brazil [3].

Barnett [4] studies the "fractured metropolis" and mentions that the old downtown zones have the most deteriorated housing and the highest crime rates and are also a place for culture and for commerce. That may seem very opposed views of the historical downtown areas, but within this duality emerges the necessity of new cities inside the same urban area. This idea is very similar to what Villaça called "main center," since both ideas come as an answer why a town's older forgotten parts while new areas are born [1]. This also happened to Manaus, in special on 1960s-1970s, when new districts attracted people because of land's low costs. One of these districts is even called "New City" (Cidade Nova in Portuguese), highlighting a similar process to what Barnett and Villaça studied $[1,4]$.

The residential areas depart from old center zones within the city due to sectorial urban specialization, especially when urban centralities become commercial areas, which causes the rising of rents and real estate speculation [1, 2]. People migrate toward the periphery, finding cheaper land prices and low rents, but this only accentuates the distance between the workforce and work places [1]. The other major problem within Latin America's old city centers is that many buildings have precarious conditions due to their seniority, so they cannot compete with a wide range of new housing and equipment in other parts of the city, especially in suburban areas [2]. However, the city's internal movement also reflects some bigger issues, like traffic gridlock [1, 4], forest's deterioration $[1,4,5]$ and the lack of infrastructure on the new housing areas [4-6].

Historical centers have great symbolic value for its residents. Hiernaux explains that old center's residents often perceive it as a place with a large amount of spaces of high symbolic value, built on traditional images of the city and local culture [3]. Hiernaux studies the historical center of Mexico City, but this idea perfectly represents Downtown Manaus characteristics, convening the idea that this neighborhood is detached from the rest of the city [3]. The idea of a center completely separated from the city makes rehabilitation even more complex, especially when there is a repressive policy of occupying the center by the less affluent sections of society, something that happened not only in Manaus, but also in Mexico City [3].

Like the Alameda Central in Mexico City, Eduardo Ribeiro Avenue (one of the Downtown Manaus main avenues) has long been a public place for sociability of the upper classes. The city's "central axis" was a prohibited area for people from the lower classes in both cities so that they also ended up encompassing most of the revolutionary demonstrations. The Alameda Central's design is a generic Latin American Champs-Elysées [3] and so is 
Eduardo Ribeiro Avenue. The city centers are a form of domination, because they are strategic places for infrastructure, commerce and other urban equipment [1]. As pointed by Sarin [7], many urban projects on the south hemisphere revolve around the demands to remove slums and to beautify the city, in order to make the cities look like European Boulevards.

The value of the center goes far beyond the symbolic value of monuments; the symbol is also the capital, through stores and banks that represent modernity and progress [1]. The historical center, in a way, has an "urban privilege," since conservation comes from the need to protect the monumental value of some specific areas [1]. It is interesting for some private entities that the historical centers are degraded so that the land rent is of very low cost, in order to enable a more intense gentrification through the privatization of several empty spaces in a historical center [1]. Frúgoli Jr mentions that "revitalization actions" often are an ideological maneuver of powers that want to remove areas of high economic interest from common urban use (such as dwelling) [8].

A similar phenomenon is happening in São Paulo and in Rio de Janeiro. In Rio de Janeiro, there was a division into two extremes, under the justification of creating a modernity project for the city: the noble area (Mauá Square and Tiradentes Square) and the poorest area (shops in the Sahara) [1]. In São Paulo, the elite created a "New Center," occupying the surroundings of Paulista Avenue [7]. The old center (formerly traditional) belonged to rich strata, but lost its qualities because it is now a place for the poorest strata, and the wealthiest sections of society occupy the New Center [1].

After this brief explanation regarding the old downtown areas, it is important to understand what these vacant lots within those districts are. For this research, we call these vacant lots "terrain vagues." Ignasí Solà-Morales describes the urban voids arising in densely urbanized areas, mostly as spatially empty and visually degraded lots as terrain vagues $[9,10]$. However, the scientific revisions employ many different expressions to refer to urban voids: terrain vague, friche urbaine, wasteland, derelict land, etc.

On France, the expression friche urbaine (roughly translated to wasteland) is a space, over five hectares, abandoned by previous human activity having had a strong impact, awaiting hypothetical reuse, located on the outskirts or at the heart of the city [11]. The Economic, Social and Regional Environmental Council (Le Conseil économique, social et régional environnemental_CESER) explains that there is a diversity of urban contexts for friche urbaine, but there is no legal definition neither an specific regulatory system for those void space within the cities.

Davies defines derelict land as a "manifestation of intentional or conscious neglect and is land that is incapable of beneficial use without treatment" [12]. This term also connects with the definition of wasteland, as described by Lynch. "Wastelands are abandoned buildings and vacant lots that appear within areas of a city that have urban infrastructure, therefore are areas where occupation of urban spaces should be efficient"—-Lynch [13].

However, the term applied on this research is "terrain vague." "Terrain vague is an expectant space that may seem abandoned and that is also delineated in the heart of the traditional city. They are patches of "non-city," spaces that are absent, ignored or fallen into disuse, alien or surviving to any modification on the structural systems of the territory." Solà-Morales [9]. A terrain vague represents an escape and an opportunity for alternation, distance for contemplation, maintaining an important cultural function of the city. These expectant spaces can be abandoned (or even just absent), as spots of non-space, and those places are ignored or left into disuse $[9,10]$. Those sites represent an opportunity for alternation maintaining a significant cultural function within the city $[9,10]$. Therefore, we opted for the use of the expression "terrain vague" since it express the cases of vacant lots in downtown.

However, the urban voids within Downtown Manaus are not an exclusivity within this city. Many other cities around the world face the same problem and apply the most diverse methods to achieve a more sustainable condition. As Galal Ahmed explains, a sustainable community is the one that can be resilient, seeking a better life quality for its inhabitants [14]. In addition, Ahmed mentions that on older downtown areas, it is important to provide more opportunities for sociability and community participation [14].

In Brazil, there are some worthy examples of urban renovations, such as Porto Alegre. As Barretto mentions [15], they employed many revitalization actions in the port area of Porto Alegre in order to turn commercial streets on walking streets. Oliveira [16] indicates that the downtown area of Porto Alegre had a rarefied occupation, even occupying a prime location in the city. For Zancheti et al. [17], Iphan's (Brazilian National Historical and Artistic Heritage Institute) "Monumenta" program sought to revalue the memory, also encouraging the occupation through the housing. The Iphan's action seems to work since, as Maraschin and Cabral [18] point out that there was a repopulation of the area, after more than two decades of housing evacuation. Thus, the challenge of repopulating Porto Alegre's waterfront area obtained a positive response thanks to the sum of forces between public power and private initiative.

Rio de Janeiro, also in Brazil, had a similar problem. The port area was degraded and empty, but here, the actions took a different direction. There was not an effort in housing the area [19], but rather a joint effort in bringing 
cultural and recreational activities to this part of the city. There was a cultural activities' reinstatement, and many new actions turned Rio de Janeiro's downtown into a cultural port [20]. Rio Fashion Week, Arte Rio and the Museum of Tomorrow, designed by Spanish neo-futuristic architect Santiago Calatrava and constructed at Pier Maua's waterfront, are examples of such endeavor. However, there was no action toward repopulating this area.

On an international level, there are examples in Europe (Rotterdam $[20,21]$ ) and the United States of America (New York City [20, 22]). New York invested on bringing back biodiversity within the city via "Designing the Edge project," which aims to restore the biodiversity to urban waterfronts [22]. Rotterdam intended to bring people back to a ruined port area, directing to re-establish housing through partnerships (social synergy, governance and institutional synergy, resource synergy), sustainability and diversity of uses (commercial, institutional, educational, housing and cultural) [22].

Since more than $50 \%$ of the global population lives in cities [23], there is a competition for space in the urban region making the green areas vulnerable for intrusions by city's growth. Since the vacant places of a city are always underused due to a lack of interest, there is a currently need of policies and economic investment on those areas, so the cities do not play on the endangerment of natural environments [23]. Even if these areas live different stages of intensity [6], people still have the right to local citizenship and it is important to plan neighborhoods for ordinary people $[6,24]$.

\section{Materials and methods}

Since the objective of this paper is to recognize the current emptying within historical downtown areas, it is important to delimit the sample, the data collection and the data analysis methodologies. The scientific approach was theoretical-conceptual and empirical. The analytical and deductive qualitative and quantitative research suits the investigation regarding historical downtown areas, in special Manaus' case study.

\subsection{Sample}

The case study method allows the selection of a sample that will enable the answer for the research main question and for the research's objectives. The sample selected for this research was the downtown area of Manaus. Manaus is the capital of Amazonas state, in Brazil. It is located on the north region of South America, within the rainforest Amazon biome. Manaus' estimated population in 2019 is $2,182,763$ people [25]. The gross domestic product (GPD) is $34,362.71 \mathrm{BRL}$, making Manaus rank 870th place among the Brazilian 5570 cities, and the first GPD on Brazil's northern region [125]. The estimated area of the territorial unit is $11,401,092 \mathrm{~km}^{2}$, with demographic density of 158.06 inhab $/ \mathrm{km}^{2}$ [25]. The Human Development Index (HDI) of Manaus is 0.737 , the highest on Brazil's northern region [25].

Manaus importance is not only regional, since it is one of the main urban areas in Brazil's north region, but is also an important city due to its proximity to Amazon rainforest. The merging of a city landscape and a natural environment is an opportunity for research. On Manaus' Downtown, the population density of the neighborhood is $77.72 \mathrm{inhab} / \mathrm{km}^{2}$, which is very low in comparison with Manaus' demographic density [25]. There are many vacant lots within this neighborhood, making this study not only imperative, but also very important to understand the conditions of Manaus urban planning.

\subsection{Data collection}

This paper has information collected via documental survey and legislation analysis. Manaus City Hall and Manaus Public Library provided the space for researching official documents and the legislation. The examination of space and urban evolution to consolidate a timeline of urban sprawling of the city employed an empirical methodology, with a comparison of maps provided by Geographical and Historical Institute of Amazonas (IGHA).

The first phase was mainly an exploratory qualitative and quantitative research. The second part was mainly an empirical research that consisted of the urban planning propositions for Downtown Manaus. This stage depended upon the collected data analysis (Sect. 3.3).

\subsection{Data analysis}

For the data analysis, it was employed a mixture of two urban approach methodologies, which will be explained as follows. The lots survey took the following steps: (1) recognition of vacant lots; (2) area inspection; (3) creation of mental map using Kevin Lynch methodology [26]; (4) lot inspection; (5) creation of guide sheets to employ a guided method to survey the vacant lots mixing Lynch's [26] and Jacobs' [27] urban terminologies. Each one of these steps results on a section of this paper. All the five stages results descriptions are in Sect. 4 "Manaus' Downtown Area: a window to the past and a reflection for the future." For the urban planning, the methodological approach is based on the research and ideas of Jane Jacobs [27], in Sect. 5 "Pod Houses project: sustainable residential (re) occupation." 


\section{Downtown Manaus: a window to the past and a reflection for the future}

Beforehand, it is important to understand where Manaus is located geographically. Manaus is the capital of Amazonas state (Fig. 1), the biggest state in Brazil in terms of size, even if it is the state with the lowest rate of number of people per hectare [25]. Brazil is the biggest country in South America (Fig. 1) and has the highest amount of virgin forest among all South American countries. That is exactly why the study of a city within a large mass of forest is so important. It is a matter of sustainability to understand how humans and the Amazon rainforest can live together in order to safeguard the Amazon biome.

Another objective of this paper is to highlight the good aspects of Manaus, in special the possibilities it holds for the future as an industrial city within the Amazon rainforest. Manaus is a regional metropolis that sets an example for many other cities on the Brazilian's north region as well as a frontier of human dialog with the forest.

\subsection{Manaus' urban development: between the void and the river}

The establishment of Manaus' city is somewhat recent; even though the first occupation took place during $1600 \mathrm{~s}$ only on September 4, 1856, the municipality of Barra do Rio Negro was renamed Manaus, becoming the new capital of the State of Amazonas (Provincial Law-Manaus $n$.
$68 / 1856)[29,30]$. The 200 -year gap resulted in a lack of urbanization in the city; the urbanization took place on the border of the Rio Negro and its tributary, the Tarumã-Açu Igarapé (Igarapé - the word applied to describe the tributary rivers in Amazon) [31]. The first district to be occupied was Tarumã (1650-1660), and the second area founded was the downtown area (named "Centro" meaning "downtown") during the short period of 1661-1670 [29].

Eduardo Ribeiro, Amazonas Governor during 1900, employed the Haussmann style to remodel the downtown area, resulting in a very aggressive (geographically and geologically/topographically) urbanization that grounded virtually all the Igarapés [32]. In Manaus, this process was taken out for pure visual beautification, masking all the unhealthiness, gradually putting away the most miserable people through state action, and the normative frameworks established by the codes of posture of 1872,1896 , 1910, 1920 and 1930 [31]. Downtown Manaus became a "ghost district" since its workers moved to distant areas within the city, making the downtown a "city of closed doors" [32].

Deusa Costa mentions that Downtown Manaus remodel was not like Pereira Passos venture in Rio de Janeiro [32]. In Manaus, the beautification was purely visual, and new model fasciae would mask unhealthiness, covering slums and poor people residences [32]. This entire people suffered the eviction by state action and by the normative frameworks established by the posture codes of 1872, 1896, 1910, 1920 and 1930 [32]. There was also an attempt to "discipline the people" by segregating the "undesirable

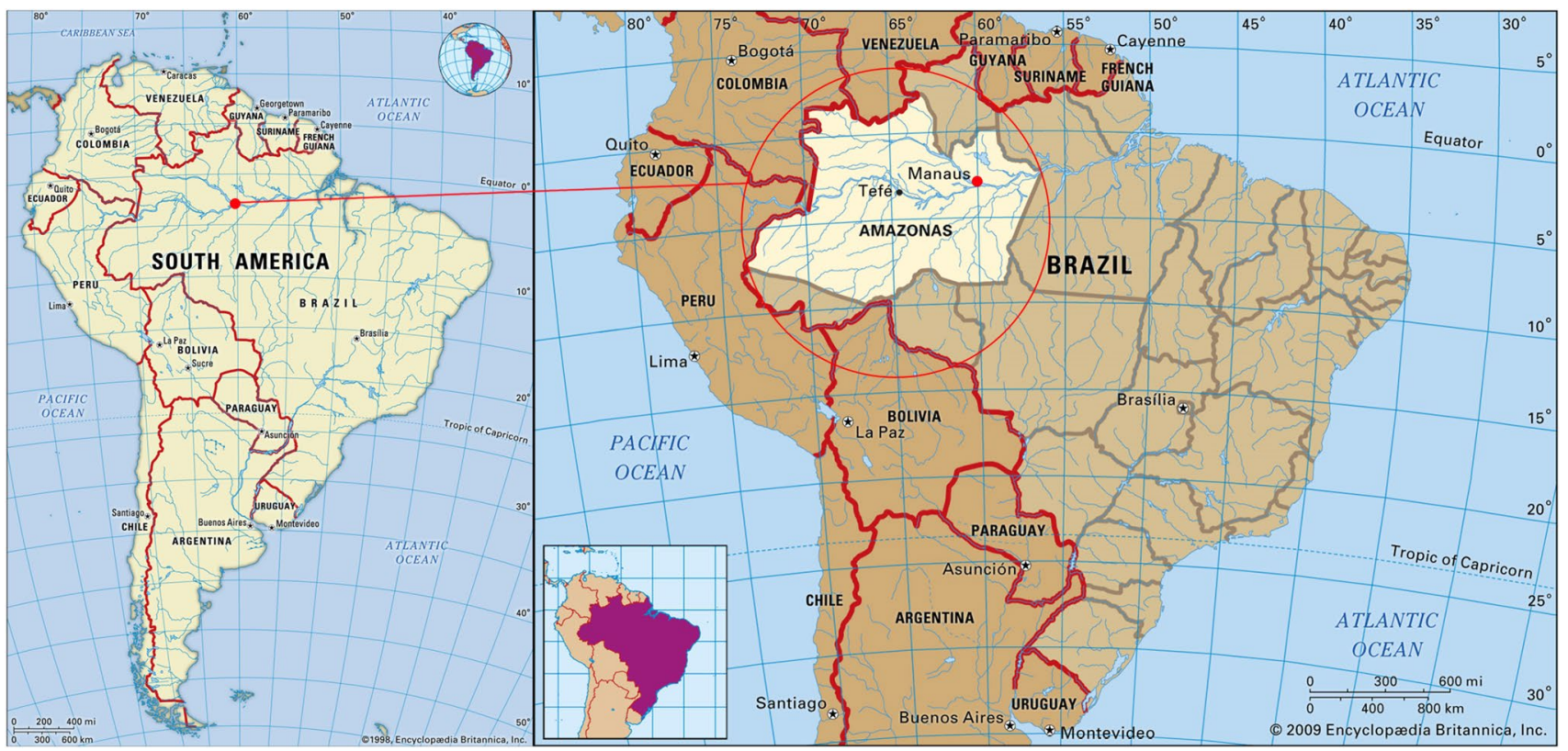

Fig. 1 Maps showing the position of Manaus within South America and within Brazil. Source Adapted from Encyclopedia Britannica Inc. [28] 
inhabitants" to other neighborhoods, such as Colônia Oliveira Machado, Constantinópolis and Bairro do Mocó [32]. The population suffered coercive measures that did not allow them to enjoy urban rights, later migrating to the city's urban fringes [32, 33].

During 1950s to the mid-1960s, people began to reoccupy Downtown Manaus, but this time using the river, making a "Floating City" in front of Downtown Manaus. The Floating City began in front of the Port of Manaus and extended to Educandos bay. José Ademir Oliveira analyzes that the origin of the Floating City relates to the threatened access to housing in the city [33]. To have an address was a luxury, and people could not afford it. Many people worked on Downtown Manaus (dockworkers, sellers, etc.), and all those people only wanted to have the right to live close to their workplaces [32].

However, in 1964, the current ruler Arthur Reis began to undo the Floating City, a process that would achieve completion by Law no. 288 of 2/27/1967 and with the creation of the Manaus's Duty-Free Zone (ZFM-Zona Franca de Manaus, in Portuguese). All the Floating City's inhabitants were relocated to peripheral neighborhoods such as Vila da Prata and Jardim dos Barés [33]. This people also serve as a contingent of labor for the new companies that would settle in the city of Manaus after the increase of the first Industrial District (1968).

Only after 1980s, Manaus began to look like the highindustrialized city we know today. The Manaus' Duty-Free Zone intended to attract more industries to Manaus and, therefore, to modernize the city. However, even after the foundation of the second Industrial District (1979), the expected future that would settle Manaus as one of the main cities of the Global South never arrived. During the 1990s, the government discourse took a very prominent change. Manaus emerged as a city within a forest, and the ecological speech applied served only to attract tourists that would only use Manaus as a bridge to reach the exotic Amazon rainforest.

In spite of that, several new districts came to be, going further inside the forest until the city reached the urban mass it has today (Fig. 2). The priority given to roads shows that urban policy in Manaus still has a strong ideology of donation, which guides the urbanization of the vast majority of Brazilian cities [5]. The new Avenue das Flores in Manaus, for example, reaches a region previously bordered by the native forest (Adolpho Ducke Forest Reserve).

This map shows the urban evolution of Manaus, from cooler colors until reaches the warmer colors. 1650-1660: Establishment of Tarumã and Tarumã-Açu districts. 1661-1670: Foundation of Centro district. 1840-1850: Foundation of São Raimundo district. 1851-1860: Foundation of Constantinópolis district (named Educandos afterward). 1880-1890: Foundation of Colonia Oliveira Machado district. 1891-1900: Foundation of Presidente Vargas, Praça 14 de Janeiro, Cachoeirinha, Morro da Liberdade, Flores and São Geraldo districts. 1920-1930: Foundation of Adrianópolis, Santa Luzia and Puraquequara districts. 1931-1940: Foundation of Parque 10 de Novembro district. 1941-1950: Foundation of Nossa Senhora Aparecida, São Francisco, Crespo, São Lázaro, Glória, Aleixo and Santo Antônio districts. 1955-1960: Foundation of Raiz, Japiim, Petrópolis, Betânia, Industrial District I, Lírio do Vale, Ponta Negra, São Jorge, Alvorada, Nossa Senhora das Graças and Chapada districts. 1961-1970: Foundation

Fig. 2 Map of urban evolution of Manaus. Source: Adapted from Medeiros [34]

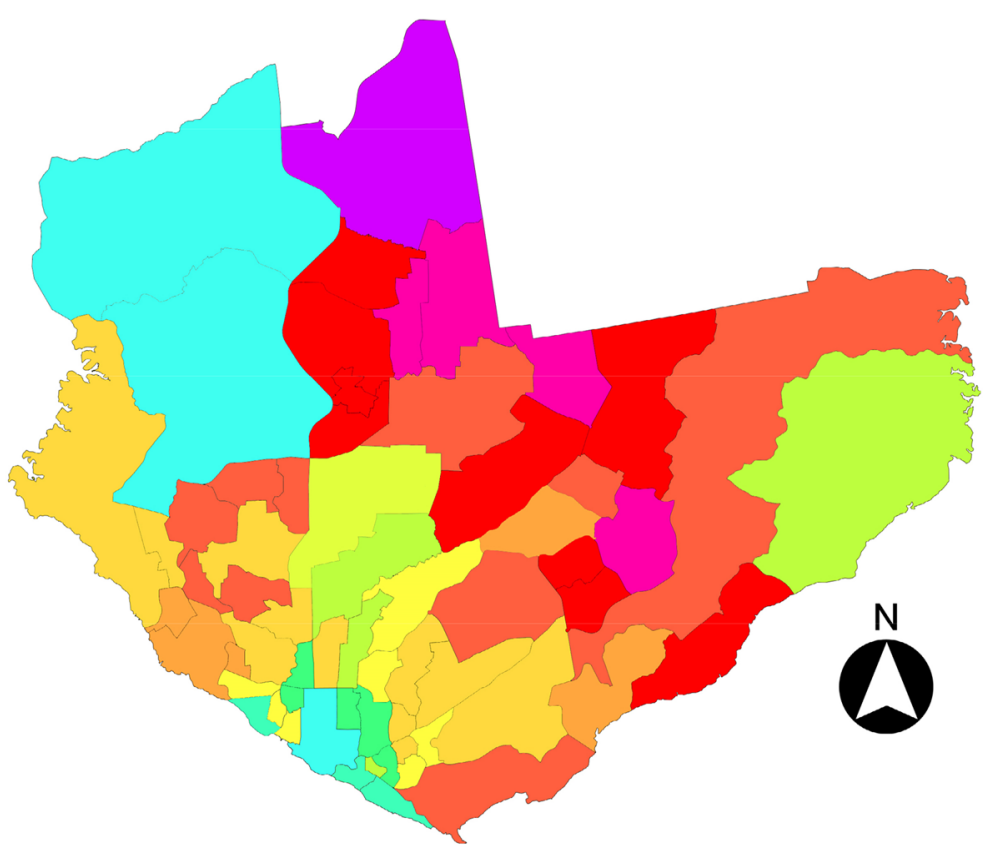

READING:

$1650-1660$

$1661-1670$

$1840-1850$

$1851-1860$

$1880-1890$

$1891-1900$

$1920-1930$

$1931-1940$

1941 - 1950

$1955-1960$

1961 - 1970

$1971-1980$

$1981-1990$

$1991-2000$

$2001-2010$

SN Applied Sciences 
of Compensa, Vila da Prata, Santo Agostinho, Mauazinho and São José Operário districts. 1971-1980: Foundation of Vila Buriti, Cidade Nova, Redenção, Dom Pedro I, Nova Esperança, Planalto, Bairro da Paz, Coroado, Industrial District II and Tancredo Neves districts. 1981-1990: Foundation of Colônia Santo Antônio, Colônia Terra Nova, Novo Aleixo, Novo Israel, Santa Etelvina, Colônia Antônio Aleixo, Zumbi dos Palmares, Armando Mendes and Jorge Teixeira districts. 1991-2000: Foundation of Cidade de Deus, Monte das Oliveiras, Nova Cidade and Gilberto Mestrinho districts. 2001-2010: Foundation of Lago Azul district.

By analyzing the map shown in Fig. 1, it is possible to understand that Manaus had grown from the edge of Negro River, reaching further until the forest. The city "sprawled" especially from 1950 until 1980, moving away from the main centrality, demanding new infrastructure projects such as larger avenues, new water supply points and even causing problems for electricity distribution networks, which took almost 20 years to adapt to the new reality of the city. (Blackouts were frequent during the 1970s, 1980s and 1990s) [33]. The city is reaching a breaking point in which the forest is at stake; people make incursions on protected forest areas to found new districts, destroying parts of the forest that were untouched by man.

The built of new residential areas on peripheral zones began firstly to accommodate workers, such as the Cidade Nova district (New City in English). Later, there was the construction of many other condominiums for wealthier classes (in Aleixo and Ponta Negra, for example) that would hold a striking resemblance to North American's planned suburbs. The occupation of the most peripheral fringes of the city is sometimes distributed to spontaneous occupations of groups considered as "invaders" (for example, the City of Lights), sometimes to structures of fortified residential condominiums in which the wealthiest classes live, isolating themselves from the Urbis. While fortified suburbs have full access to infrastructure and social improvements, areas designed for the accommodation of workers, which function as sleeping quarters (which serve only to receive workers at the end of the working day) [35], do not have access to all services needed, lacking the most basic structures, such as hospitals, schools and transportation. [5, 36].

In Manaus, several orthodox city plans, introduced by Europeans and North Americans, were adopted, even if they are unsuited for the region. Fainstein and DeFilippis explain that such type of urban planning that only works toward aesthetics, efficiency and modernization uses the zoning as a regulatory system to deny certain groups the access to rights and services [6]. The North American and European ways to make urban plans are often only assumptions regarding urban contexts that are completely different from other parts of the world [6]. This is one of main causes for the inequalities and gaps between the different strata that forms the cities [6]. However, "cities are fantastically dynamic places" [6], so even if the urban plans applied to Manaus are based upon Global North's theories, the city itself changes to adapt itself outside this boxed orthodox methodology. These template-planning models create a false sense of diversity and end up erasing local qualities and destroying the local sense of multiplicity [37].

All those city plans and imported theories made Manaus lose its connection to the water basin [33]. Manaus people and even the city planners often look away from the rivers and Igarapés. Manaus inhabitants consider the river inhospitable and stain, even if all foreign people that come to visit the city see the water as a blessing. Since Downtown Manaus has many points of connection with Negro River (it bathes the whole waterfront area), people see the downtown as a degraded place where they only go if they really need to be there [32]. This abandonment made lots in downtown cheaper but unwanted for housing, turning the area a commercial district by day and a void area by night. That is the reason why this section name is "Manaus' urban development: between the void and the river." Even today, the downtown area is a major void within the city.

The extensive peripheries of the city, combined with the disastrous traffic problems, demonstrate the inefficiency of mass transportation as a structural crisis of modern urban discourse in Manaus. For that matter, it is essential to find new ways for the urban planning in Manaus, seeking more sustainable ways to manage the city. The occupation of terrain vagues on areas with consolidated infrastructures, such as the downtown area. Downtown Manaus has all the urban types of equipment necessary for the population (such as hospitals, schools and police stations), afforestation, basic sanitation, water supply and excellent pavement which is a key for that endeavor. Manaus' current demographic density is $158.06 \mathrm{in} / \mathrm{km}^{2}$, while the downtown area demographic density is $77.72 \mathrm{in} / \mathrm{km}^{2}$ [25].

\subsection{Manaus historical downtown: terrain vagues survey}

As explained in Sect. 3, the lots survey took five steps, to understand the terrain vagues of Downtown Manaus. The methodological steps are: (1) recognition of vacant lots; (2) area inspection; (3) creation of mental map using Kevin Lynch methodology [26]; (4) lot inspection; and (5) creation of guide sheets for each lot.

Since all interventions propose intent to alter the existing realities [6], it is really important to understand the meaning of this places (within the urban area and within people's memories). Fainstein and DeFilippis define place as a "three-dimensional urban space that is cherished by 
the people who inhabit it" [6]. They do not define the scale, but they talk about the attachment to that place. The terrain vagues on downtown area are "almost places" due to the stages of intensity that a "place" retains during the time [6].

For the recognition of terrain vagues within downtown (first step), it is important to watch the census results. Since late 1990s, Downtown Manaus has a negative geometric growth rate-1996-2000: - 1.31; 2000-2007: - 2.51; 2007-2010: - 0.12 [19]. According to IBGE (Brazilian Institute of Geography and Statistics), $11.95 \%$ of the properties of the center are vacant (9538 occupied homes and 2580 vacant dwellings) [25]. The vacating of these spaces occurred due to the most diverse judicial issues: owners' registration in the Municipality Active Debt, due to lack of payment of the property tax and other taxes [38].

To illustrate the state of vacancy on downtown, Table 1 lists the number of vacant lots and vacant buildings inspected.

Area 1 encloses twelve paths (streets, avenues, bystreets and alleys). Area 1 encompasses the following streets, avenues, bystreets and alleys: Padre Agostinho, Visconte de Mauá, Tamandaré, Padre Ghisland, Luiz Antony, Itamaracá, Henrique Antony, Governador Vitório, Frei José dos Inocentes, Coronel Salgado, Comendador Alexandre Amorin, 7 de Setembro. There are 43 vacant buildings and 13 vacant lots on this area. The vacant structures are mainly old constructions prior to 1930 that need much reworking to be safe for use.

Area 2 surrounds seven paths. Area 2 includes the following streets, avenues, bystreets and alleys: Silva Ramos, Ramos Ferreira, Major Gabriel, Leonardo Malcher, Emílio Moreira, Tapajós and Simão Bolívar. There are 38 vacant buildings and 29 vacant lots on this area. The vacant buildings are manly modernist structures from 1950 to 1960. Even if the said buildings are newer, they still need major structural refit to be safe for use.

Area 3 enfolds fifteen paths. Area 3 contains the following streets, avenues, bystreets and alleys: Saldanha Marinho, Rui Barbosa, Lobo D'Almada, José Clemente, Joaquim Sarmento, Dona Libânia, 10 de julho, Barroso, Henrique Martins, 24 de Maio, Monsenhor Coutinho,

Table 1 Number of vacant buildings and vacant lots in Downtown Manaus. Source: Medeiros [40]

\begin{tabular}{lll}
\hline $\begin{array}{l}\text { Area } \\
\text { num- } \\
\text { ber }\end{array}$ & $\begin{array}{l}\text { Vacant } \\
\text { build- } \\
\text { ings }\end{array}$ & Vacant lots \\
\hline 1 & 43 & 13 \\
2 & 38 & 29 \\
3 & 69 & 20 \\
4 & 35 & 2 \\
5 & 26 & 9 \\
\hline
\end{tabular}

Ferreira Pena, Joaquim Nabuco, Epaminondas and Getúlio Vargas. There are 69 vacant buildings, from different times; some of them are ready for use, and other edifices still need amendments. There are 20 vacant lots on this area.

Area 4 encloses nine paths. Area 4 encompasses the following streets, avenues, bystreets and alleys: Teodoreto Souto, Rocha Santos, Marechal Deodoro, Marcílio Dias, Doutor Moreira, Floriano Peixoto, Quintino Bocaiuva, Pedro Botelho and Miranda Leão. There are 35 vacant buildings and two vacant lots on this area. The buildings are mostly ruined structures that would need major restoration and even new structural reinforcements.

Area 5 surrounds ten paths. Area 5 covers the following streets, avenues, bystreets and alleys: Lima Bacuri, Leovegildo Coelho, Lauro Cavalcante, Isabel, José Paranaguá, Doutor Almínio, Andradas, Cândido Marino, Barão de São domingos and Caxangá. There are 26 vacant buildings and nine vacant lots on this area. Just like Area 4, the buildings need restoration and structural reinforcements.

It is imperative to take note that there are more streets, avenues, bystreets and alleys at Downtown Manaus; however, this investigation objective is to point the areas that have more terrain vagues, so the exploratory research pointed out the five areas (73 vacant lots and 211 vacant buildings) [38]. The map below graphically identifies the five areas (Fig. 3).

The second and the third steps on the methodology are: (2) area inspection; (3) creation of mental map using Kevin Lynch methodology [26]. Lynch [26] proposes the creation of mental maps that make possible the legibility of cityscapes. The creation of mental maps depends on five elements: (1) paths; (2) edges; (3) districts; (4) nodes; and (5) landmarks. Paths are the routes to move throughout the city, while edges are the boundaries that separate portions of a city. As Kevin Lynch mentions, districts are zones with similar characteristics, while nodes are strategic points within the city that bring together several people [26]. The landmarks are external points of orientation that are easily spot out as physical objects on the landscape [26].

The application of this method to make a mental map of one of the studied areas is shown in Fig. 4. The map illustrates the area around "Igarapé de São Vicente" (São Vicente Water Course), pointing the following paths: Frei José dos Inocentes Street, Governado Vitório Street, Luiz Antony Street, Padre Ghisland Street and José Casemiro Street.

The mental map has the following reading: Orange stripes mark mixed-use areas/districts; pink stripes mark residential areas (housing districts); and blue stripes mark commercial areas/districts. Green stars point the landmarks: 1-Military Academy; 2-Dom Bosco Catholic School; 3-Liberty Palace, currently a museum; 4Dom Pedro II Square; 5-Rio Branco Palace (government 


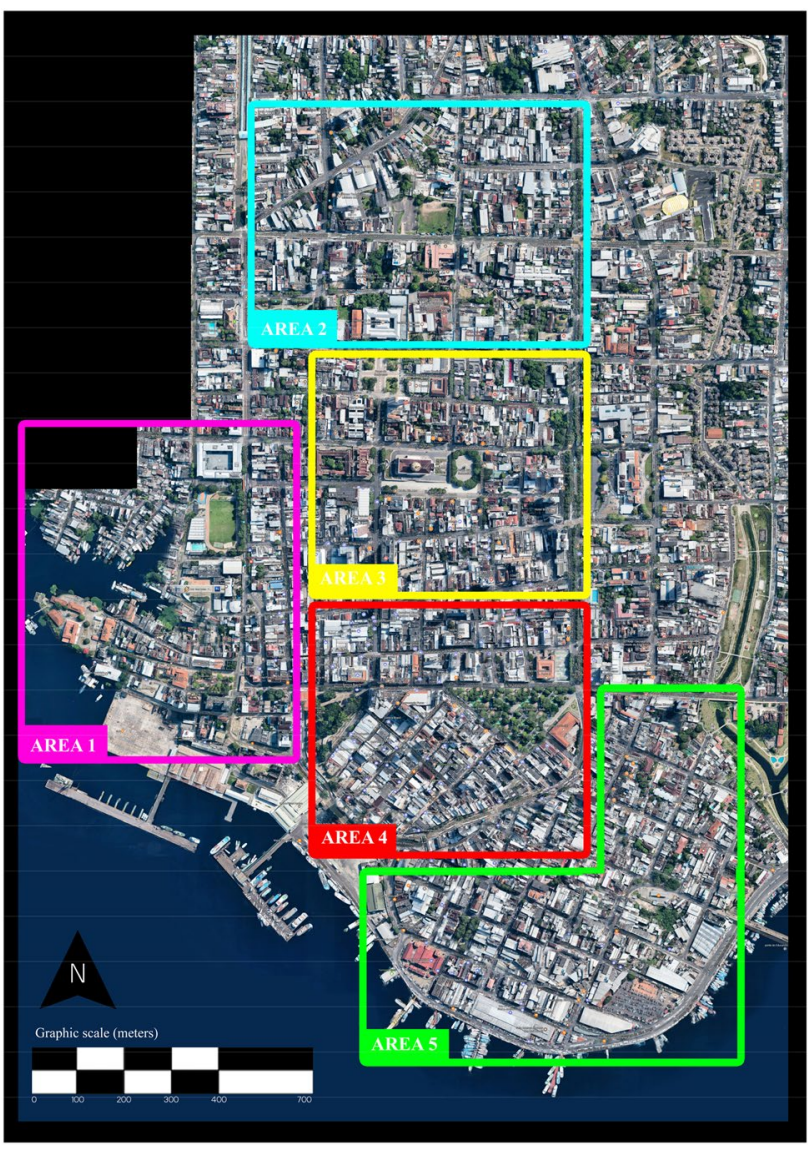

Fig. 3 Downtown Manaus map with the five research areas highlighted. Source Medeiros [39]

building); 6-National Institute of Social Insurance. Two stripes and a dash mark the edges that follow São Vicente Water Course. The water course insulates two land masses that are mainly occupied by housing districts, serving as an edge that keeps two related spaces geographically separated. Next to the mental map, there is a satellite picture showing the area, for comparison matter.

Each one of the areas chosen for the architectural and urban interventions received a mental map study. Figures 5, 6, 7, 8 and 9 illustrate the application of Lynch's [26] method.

The mental map has the following reading: Orange stripes mark mixed-use areas/districts; pink stripes mark residential areas (housing districts); and blue stripes mark commercial areas/districts. Green stars point the landmarks: 1-Uninorte's University Campus; 2-SEBRAE (Brazilian Micro and Small Business Support Service). Leonardo Malcher Avenue appears as an edge since there is intense bus traffic during all day. The node pointed on purple on the intersection between Leonardo Malcher Avenue and Tapajós Street is due to four bus stops that converge on this area, making this a point of conflict.

The mental map has the following reading: Orange stripes mark mixed-use areas/districts; pink stripes mark residential areas (housing districts); and blue stripes mark commercial areas/districts. Green stars point the landmarks: 1-Saudade Square; 2-IEA (Institute of Education of Amazonas); 3-Uninorte's University Campus. The purple point is a node that appears due to the intense vehicular traffic on Ferreira Pena Street, which often conflicts with Leonardo Malcher Avenue's bus traffic.

The mental map has the following reading: Orange stripes mark mixed-use areas/districts; pink stripes mark residential areas (housing districts); and blue stripes mark commercial areas/districts. Green stars point the landmarks: 1-Lato Sensu Private School; 2-Adalberto Valle Educational Center; 3-Life health center and fitness center; 4-SAMEL Hospital. Getúlio Vargas Avenue functions as an edge because it is a large avenue with dense
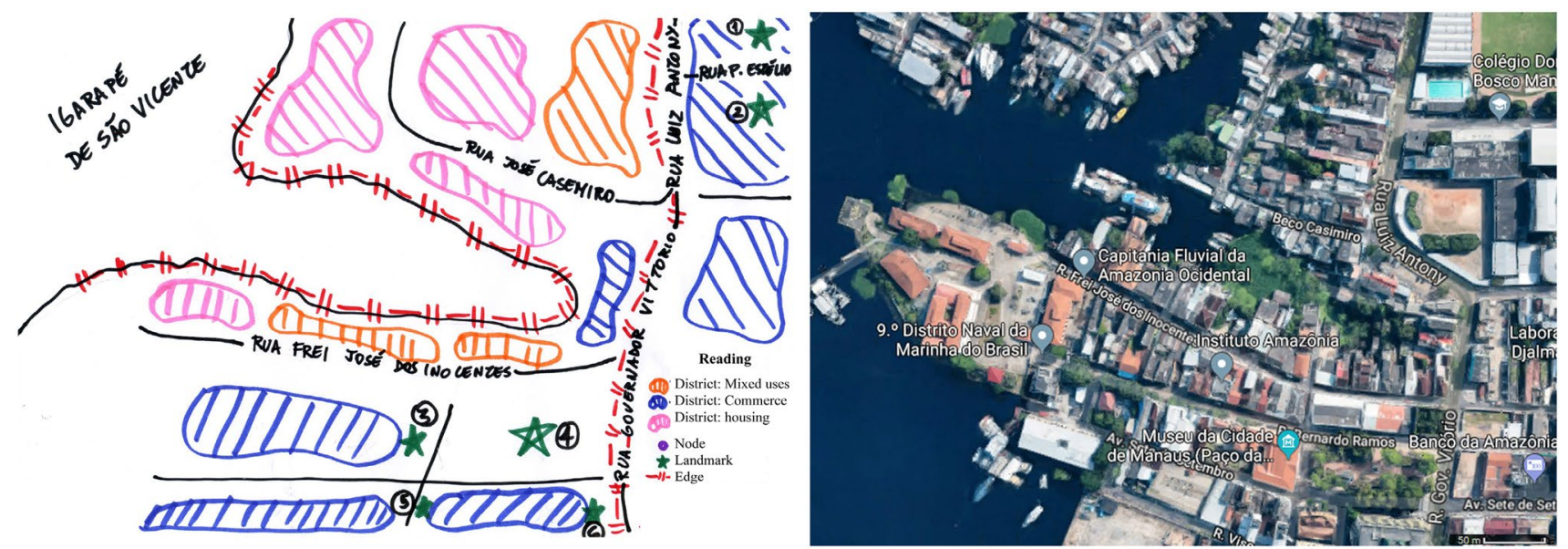

Fig. 4 Mental map and Google Maps image for comparison, “Igarapé de São Vicente Area." Source Medeiros [39] 

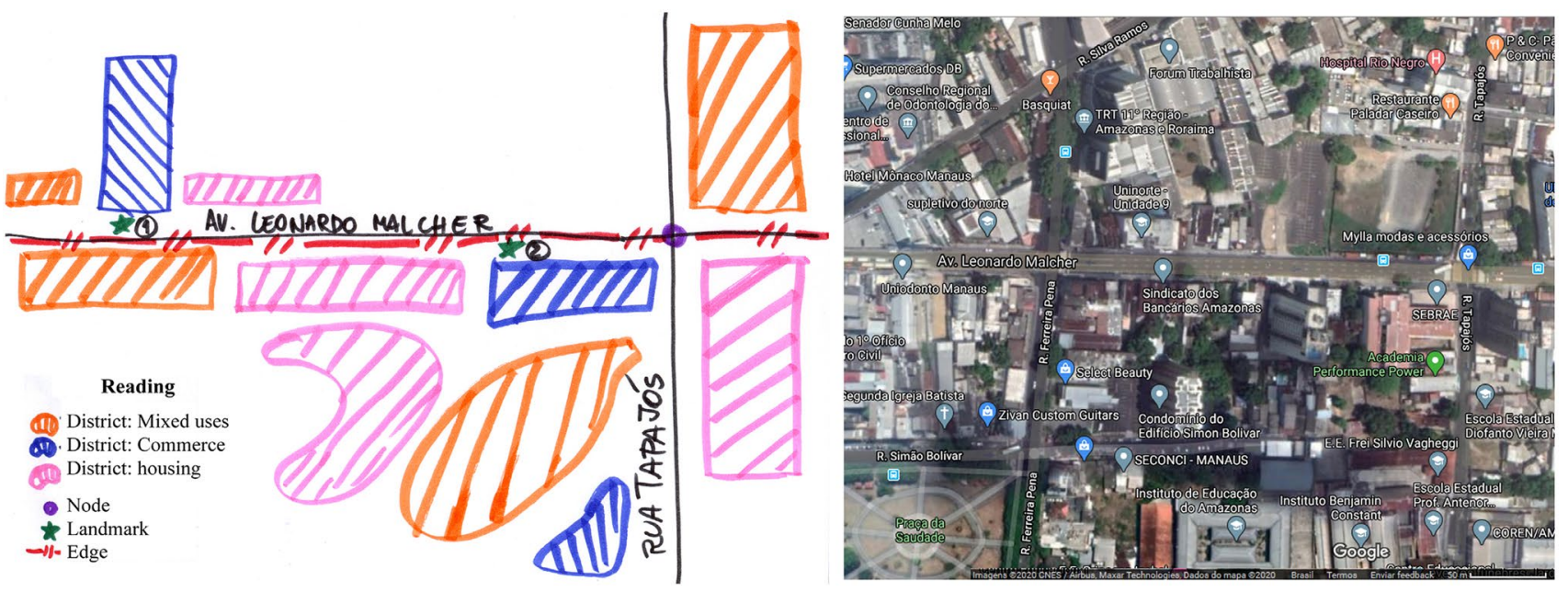

Fig. 5 Mental map and Google Maps image for comparison, Leonardo Malcher avenue area. Source Medeiros [39]
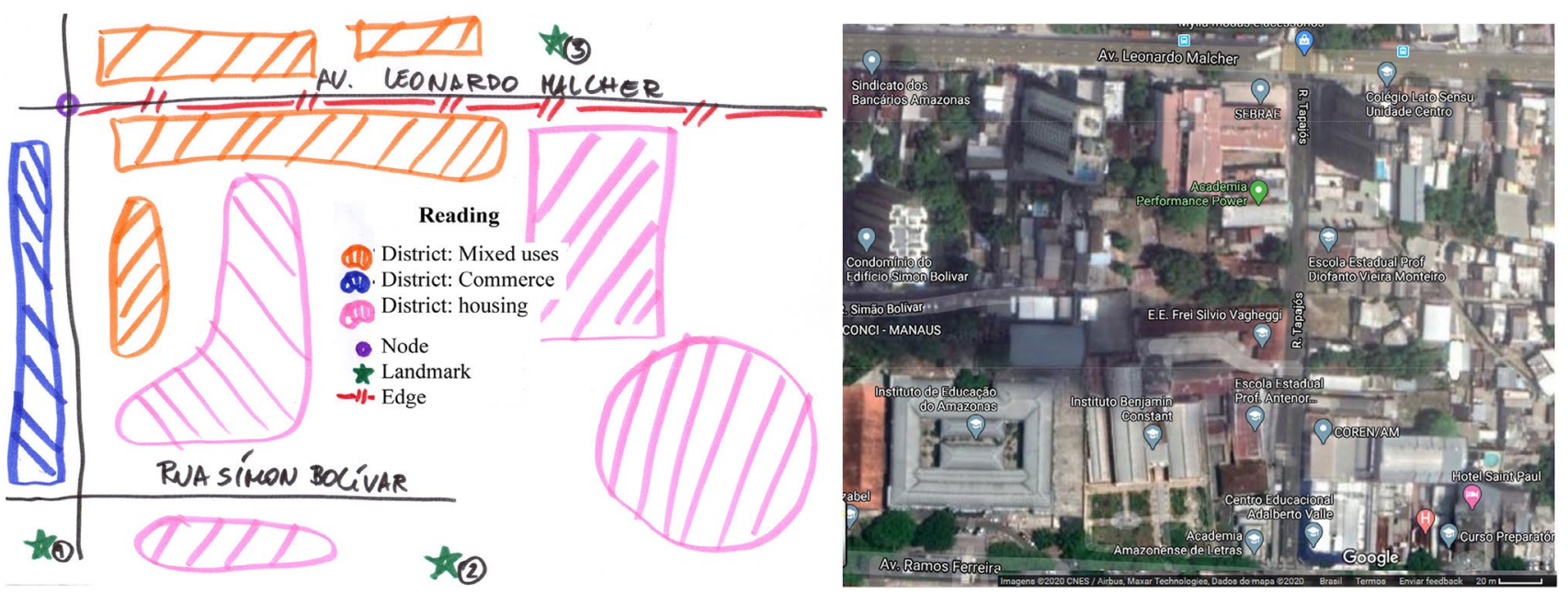

Fig. 6 Mental map and Google Maps image for comparison, Símon Bolívar Street area. Source Medeiros [39]

afforestation. The two nodes pinpointed on this map relate to Getúlio Vargas Avenue traffic. Only the downtown-neighborhood road (right) of Getúlio Vargas Avenue, has intense circulation due to the bus lines traffic. The neighborhood-downtown way (left) does not have traffic jams, since it is a less common route to arrive downtown.

The mental map has the following reading: Orange stripes mark mixed-use areas/districts; pink stripes mark residential areas (housing districts); and blue stripes mark commercial areas/districts. Green stars point the landmarks: 1-Luso Sporting Club; 2-CAUA (UFAM's Art Center); 3-São Sebastião Catholic Church. There is a node (purple point) near São Sebastião Catholic Church since this church is a very important liturgical center in Manaus. Tapajós Street often closes due to this church's celebrations. This node represents a centering spot [6], a small-scale territory where a series of actions happen several times during the years [6]. There is a sense of sacred on these spaces of gathering and/or encounter that is the main reason why planners should avoid the erasure of these places due to gentrification since it would mean the destruction of human relations [6].

The mental map has the following reading: Orange stripes mark mixed-use areas/districts; pink stripes mark residential areas (housing districts); and blue stripes mark commercial areas/districts. Green stars point the landmarks: 1-IEA (Institute of Education of Amazonas); 2-Palace of Justice, currently a museum; 3-Amazonas' Theatre; 4-São Sebastião Square; 5-São Sebastião Catholic Church; 6-CAUA (UFAM's Art Center); 7-Luso Sporting Club. Two stripes and a dash mark the edges that follow 10 de Julho Street mark an edge since most people perceive that after this street starts São Sebastião Square. The nodes (purple points) mark the crossroads 


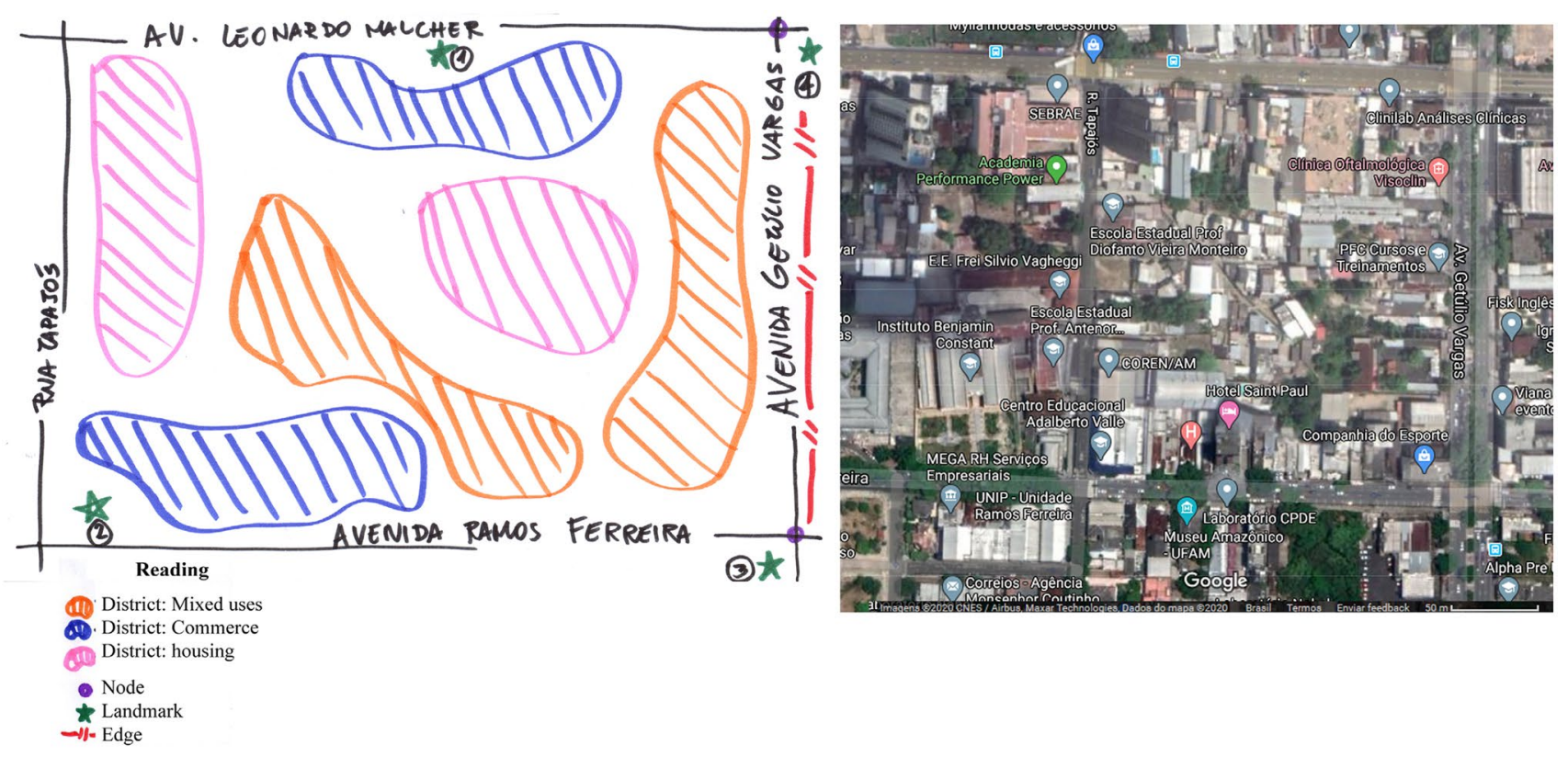

Fig. 7 Mental map and Google Maps image for comparison, Leonardo Malcher Avenue Area and Ramos Ferreira Avenue square. Source Medeiros [39]
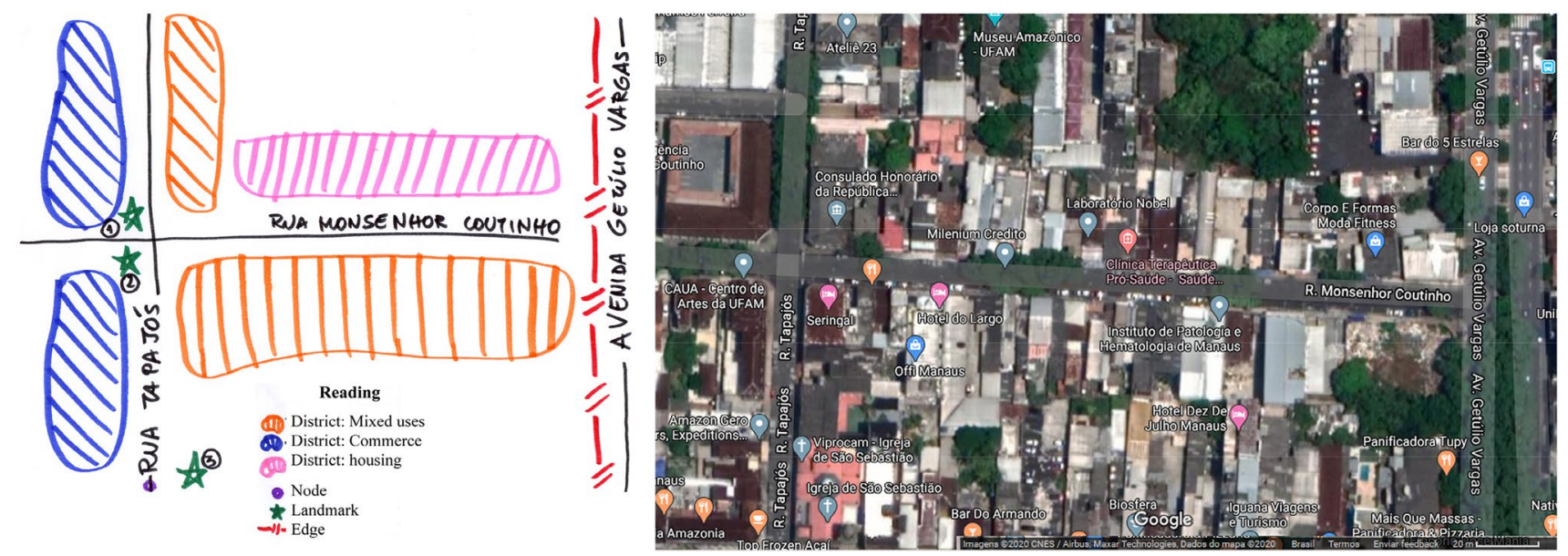

Fig. 8 Mental map and Google Maps image for comparison, Getúlio Vargas avenue area. Source Medeiros [39]

that close due to São Sebastião Catholic Church's and Amazonas'Theatre's festivities.

Since the main reason of this study is to understand the terrain vagues of Manaus, the survey continues through fourth and fifth steps: (4) lot inspection; (5) creation of guide sheets for each lot. The following guide sheets are part of the field research and point the aspects: Variety of Urban Equipment Near, Proximity of Urban Equipment, Safety (Feeling of Safety), Residential Inhabitation, Public Noise (Noise Volume), Ventilation (Wind), Passersby (walkers, cyclists, etc.), Light Vehicles (cars, small buses, bicycles, motorcycles), Heavy Vehicles (buses, trucks) and Tourist Appropriation.

There was a survey of the 73 vacant lots listed in Table 1, within the five areas highlighted in Fig. 3. However, we only choose five lots among the 73 , since this was an undergraduate project. Each one of the five lots guide sheets shows the benefits of each one of the lots, aiming to demonstrate the possibilities of uses (housing, public parks, public structures, etc.).

The first lot is on 10 de Julho St. The results are: (1) Variety of Urban Equipment-excellent (many options), 

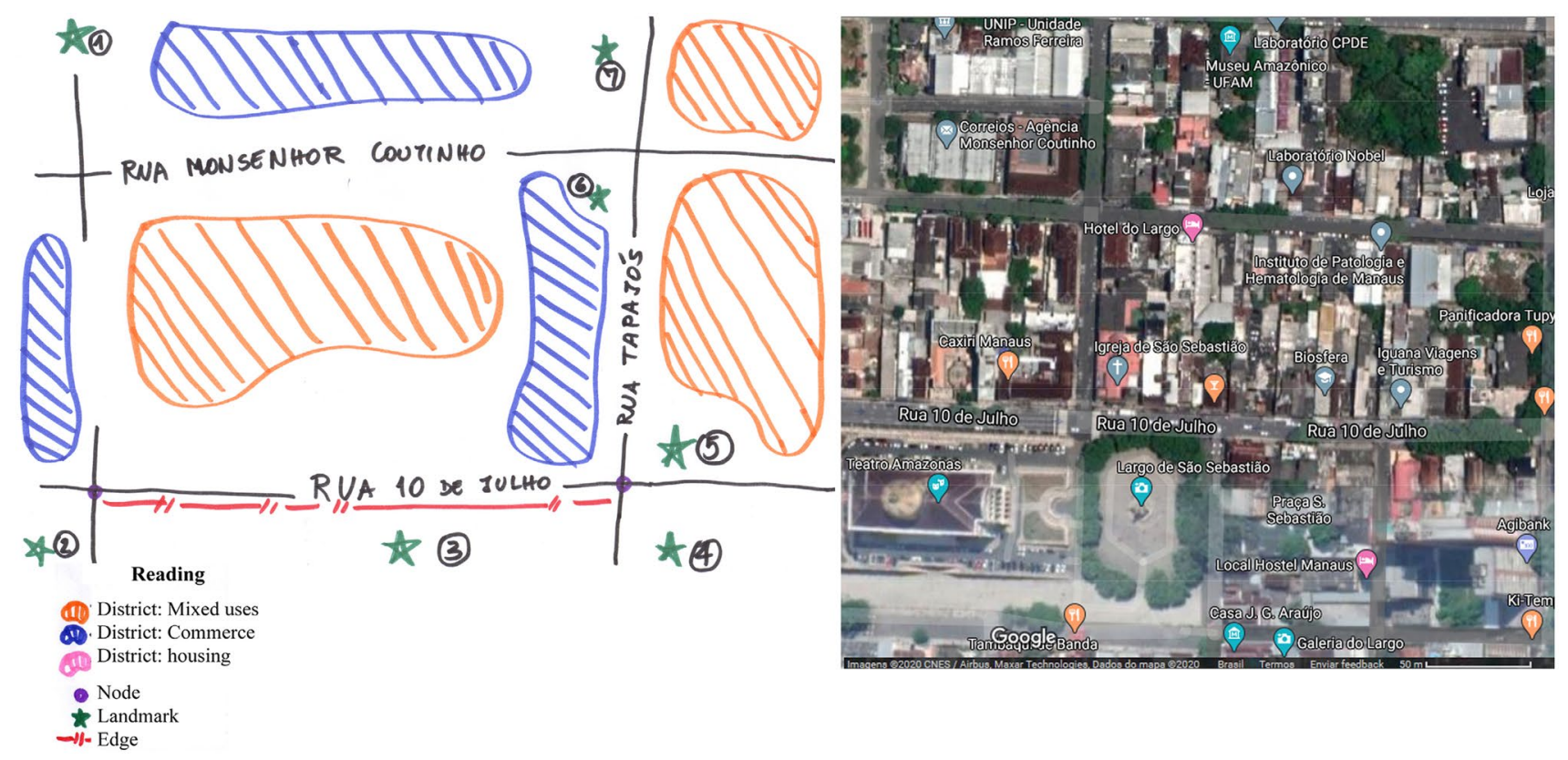

Fig. 9 Mental map and Google Maps image for comparison, Amazonas Theatre vicinity area. Source Medeiros [39]

(2) Proximity of Urban Equipment-very close, (3) Safety (Feeling of Safety) - high, (4) Residential Occupationlow, (5) Public Noise (Noise Volume)—morning (medium); afternoon (medium); night (medium), (6) Ventilation (Wind)-morning SW (high); afternoon SE (medium); night NW (high), (7) Passersby (walkers, cyclists)—morning (many); afternoon (many); night (many), (8) Commercial Appropriation-morning (medium); afternoon (medium); night (high), (9) Light Vehicles (cars, small buses, bicycles, motorcycles)-morning (medium); afternoon (medium); night (medium), (10) Heavy Vehicles (buses, trucks)— morning (low); afternoon (low); night (low), (11) Tourist Appropriation-high (Fig. 10).

The second lot is on A. Getúlio Vargas. The results are: (1) Variety of Urban Equipment-excellent (many options), (2) Proximity of Urban Equipment-very close, (3) Safety (Feeling of Safety) - high, (4) Residential Occupationhigh, (5) Public Noise (Noise Volume)—morning (medium); afternoon (medium); night (low), (6) Ventilation (Wind) morning SW (high); afternoon NE (medium); night E (high), (7) Passersby (walkers, cyclists)—morning (many); afternoon (many); night (low), (8) Commercial Appropriationmorning (medium); afternoon (medium); night (low), (9) Light Vehicles (cars, small buses, bicycles, motorcycles) morning (high); afternoon (high); night (low), (10) Heavy Vehicles (buses, trucks)—-morning (high); afternoon (low); night (high), (11) Tourist Appropriation-low (Fig. 11).

The second lot is on Frei José dos Inocentes St. The results are: (1) Variety of Urban Equipment-medium (most museums and public buildings), (2) Proximity of
Urban Equipment-not very close, (3) Safety (Feeling of Safety)—medium, (4) Residential Occupation-medium, (5) Public Noise (Noise Volume)-morning (low); afternoon (low); night (low), (6) Ventilation (Wind)-morning W (high); afternoon W (medium); night W (high), (7) Passersby (walkers, cyclists)-morning (low); afternoon (low); night (low), (8) Commercial Appropriation-morning (low); afternoon (low); night (low), (9) Light Vehicles (cars, small buses, bicycles, motorcycles)-morning (low); afternoon (low); night (low), (10) Heavy Vehicles (buses, trucks)-morning (low); afternoon (low); night (low), (11) Tourist Appropriation-low (Fig. 12).

For Leonardo Malcher, the results are: (1) Variety of Urban Equipment-excellent (many options), (2) Proximity of Urban Equipment-very close, (3) Safety (Feeling of Safety)-medium, (4) Residential Occupation-medium, (5) Public Noise (Noise Volume)—morning (medium/ medium); afternoon (high/medium); night (low/low), (6) Ventilation (Wind)-morning SW (medium/medium); afternoon SE (low/low); night NE (high/high), (7) Passersby (walkers, cyclists)-morning (many); afternoon (many); night (little to none), (8) Commercial Appropriationmorning (high/medium); afternoon (high/medium); night (medium/medium), (9) Light Vehicles (cars, small buses, bicycles, motorcycles) — morning (heavy/heavy); afternoon (heavy/heavy); night (medium/low), (10) Heavy Vehicles (buses, trucks)—-morning (heavy/low); afternoon (heavy/ low); night (medium/low), (11) Tourist Appropriation-low.

The figure shows the example of a lot between Leonardo Malcher Avenue and Símon Bolívar Street. For 

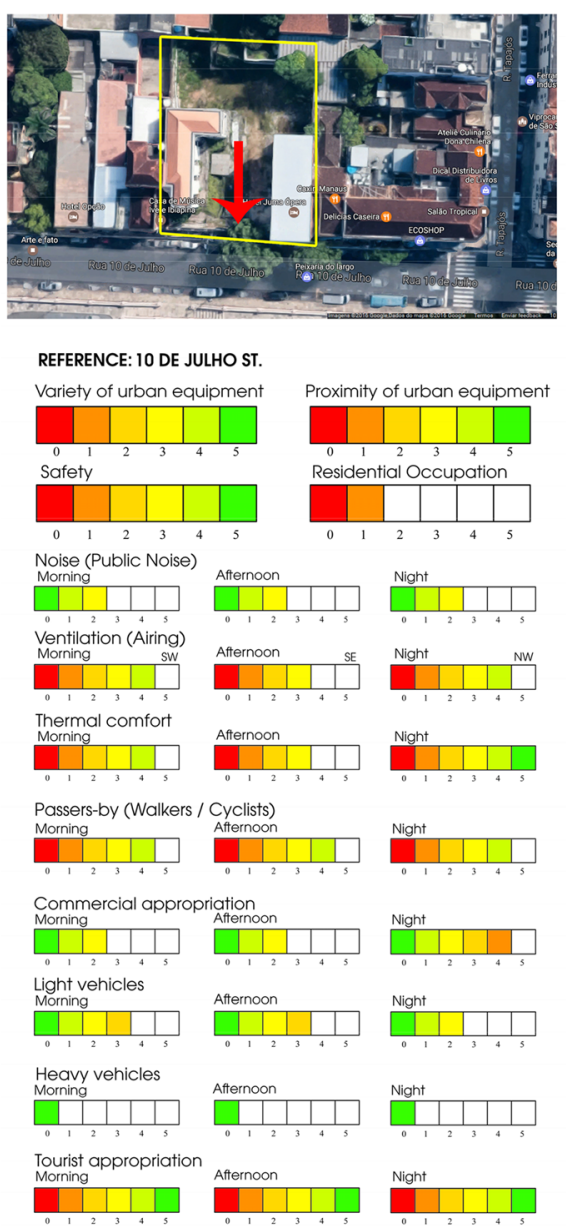

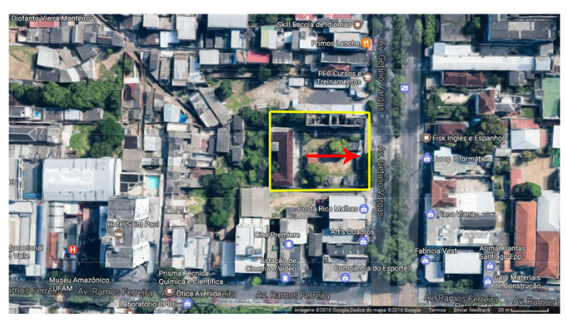

REFERENCE: A. GETÚLIO VARGAS

Variety of urban equipment Proximity of urban equipment

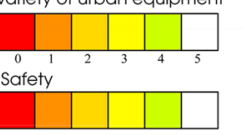

Noise (Public Noise)
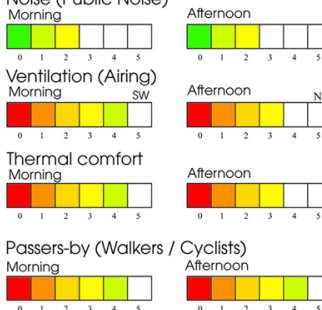

Commercial appropriation
Morning

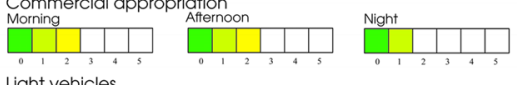

Light vehicles

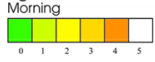

Heavy vehicles
Morning

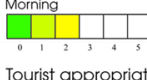

\begin{tabular}{l} 
Tourist appropriatio \\
Morning \\
\hline
\end{tabular}
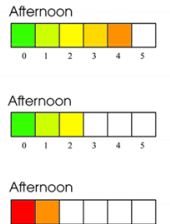

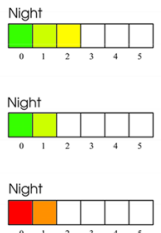

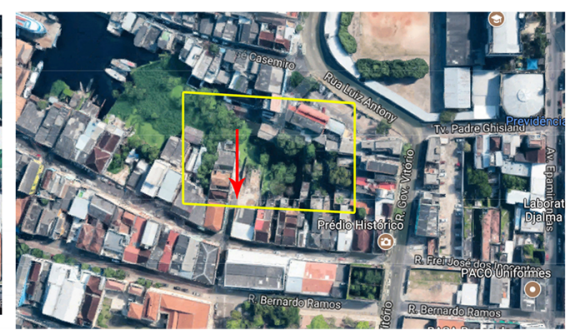

REFERENCE: FREI JOSÉ DOS INOCENTES ST.

Variety of urban equipment Proximity of urban equipment

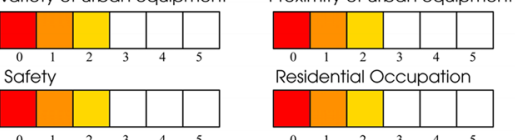

Noise (Public Noise)
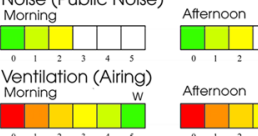

Thermal comfort
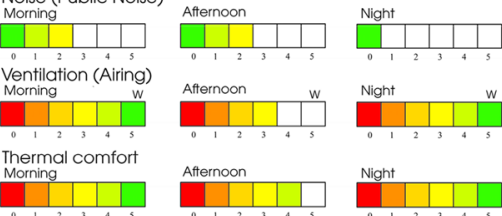

Passers-by (Walkers / Cyclists)

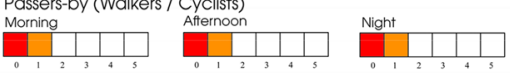

Commercial appropriation
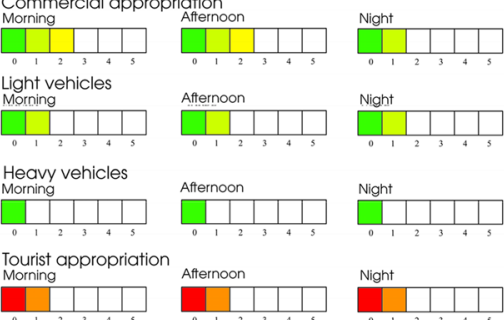

Night

Fig. 10 Guide sheets for three areas. Source Medeiros [39]

the first lot, the results are: (1) Variety of Urban Equipment-excellent (many options), (2) Proximity of Urban Equipment-very close, (3) Safety (Feeling of Safety) high, (4) Residential occupation-high, (5) Public Noise (Noise Volume)-morning (high/low); afternoon (high/ low); night (low/low), (6) Ventilation (Wind)-morning SE (medium/medium); afternoon SE (low/low); night SE (high/high), (7) Passersby (walkers, cyclists)—morning (little to none); afternoon (little to none); night (little to none), (8) Commercial Appropriation-morning (low/ low); afternoon (low/low); night (low/low), (9) Light Vehicles (cars, small buses, bicycles, motorcycles)-morning (heavy/low); afternoon (heavy/low); night (medium/low), (10) Heavy Vehicles (buses, trucks)—morning (heavy/low); afternoon (heavy/low); night (medium/low), (11) Tourist Appropriation-low.

For the IEA lot, the results are: (1) Variety of Urban Equipment-excellent (many options), (2) Proximity of Urban Equipment-very close, (3) Safety (Feeling of Safety) high, (4) Residential Occupation-high, (5) Public Noise (Noise Volume)-morning (low); afternoon (low); night (low), (6) Ventilation (Wind)—-morning SE (high); afternoon SE (low); night SE (high), (7) Passersby (walkers, cyclists)morning (none); afternoon (none); night (none), (8) Commercial Appropriation-morning (low); afternoon (low); night (low), (9) Light Vehicles (cars, small buses, bicycles, motorcycles) - morning (low); afternoon (low); night (low), (10) Heavy Vehicles (buses, trucks) — morning (low); afternoon (low); night (low), (11) Tourist Appropriation-low.

For this area, the results are: (1) Variety of Urban Equipment-excellent (many options), (2) Proximity of Urban Equipment-very close, (3) Safety (Feeling of Safety)-medium/medium, (4) Residential Inhabitation-medium/medium, (5) Public Noise (Noise Volume)-morning (medium/medium); afternoon (medium/medium); night (low/low), (6) Ventilation (Wind)-morning NE (high/high); afternoon NE (medium/medium); night NE (high/high), (7) Passersby (walkers, cyclists)—-morning (many); afternoon (many); night (medium), (8) Commercial Appropriation-morning (medium/medium); afternoon (medium/medium); night (medium/medium), (9) Light Vehicles (cars, small 


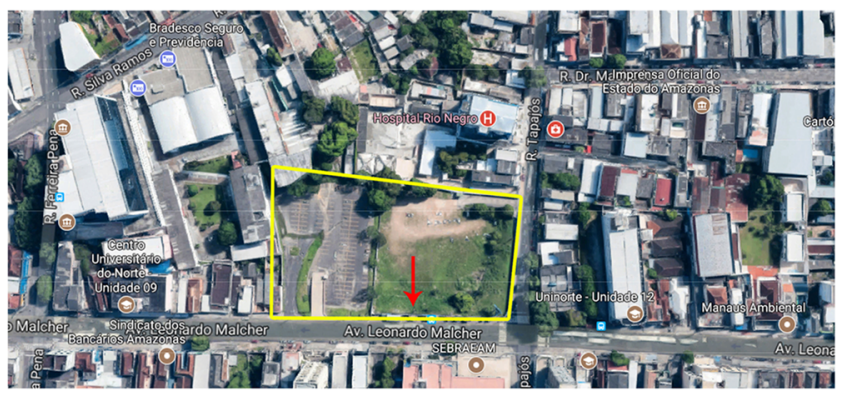

REFERENCE: A. LEONARDO MALCHER

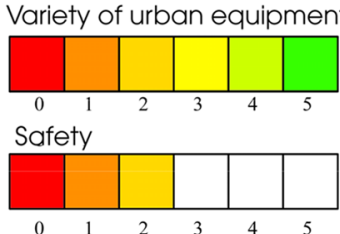

Proximity of urban equipment

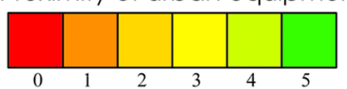

Residential Occupation

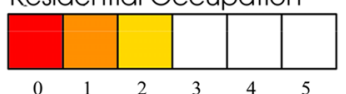

Noise (Public Noise)
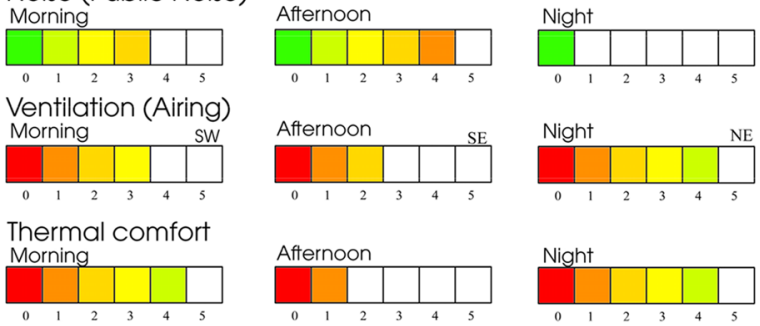

Passers-by (Walkers / Cyclists)
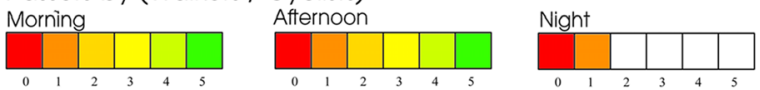

Commercial appropriation
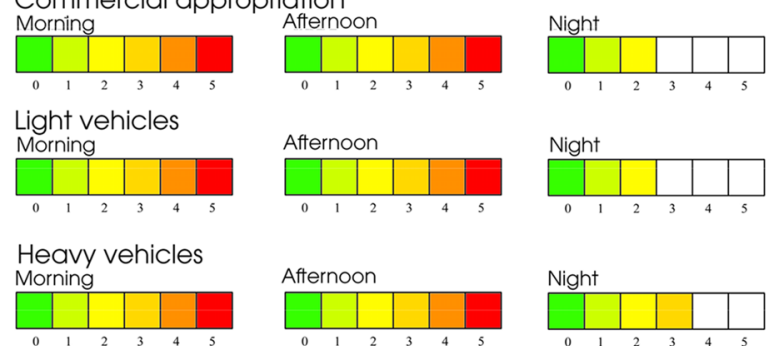

Tourist appropriation
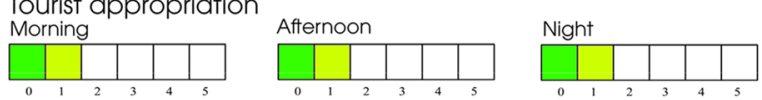

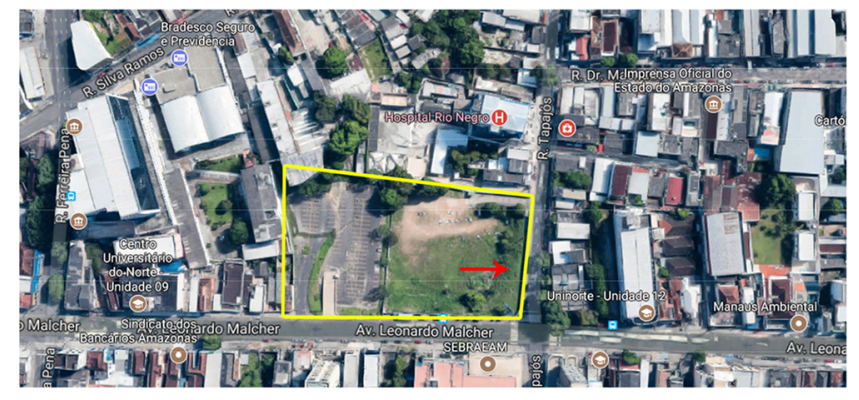

REFERENCE: A. LEONARDO MALCHER

Variety of urban equipment

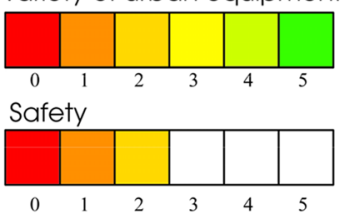

Proximity of urban equipment

Noise (Public Noise)

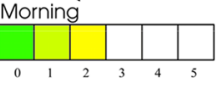

Ventilation (Airing)
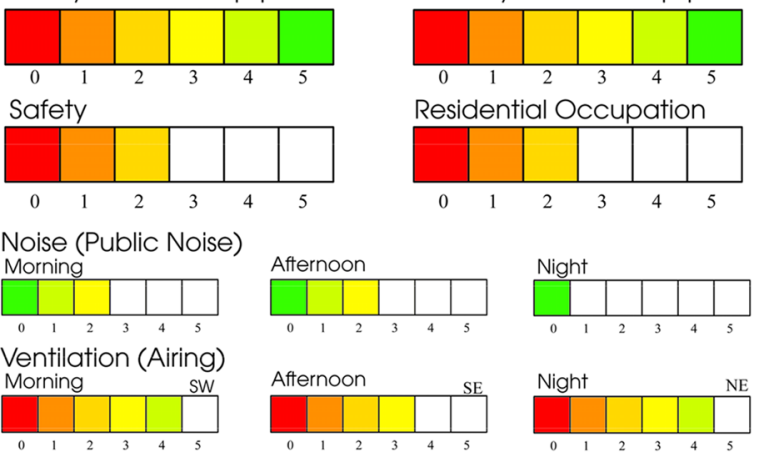

Residential Occupation

Thermal comfort
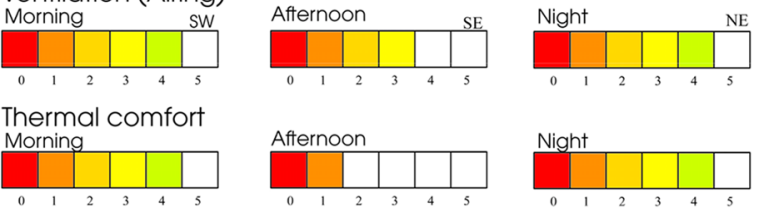

Passers-by (Walkers / Cyclists)
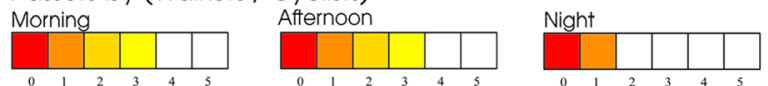

Commercial appropriation
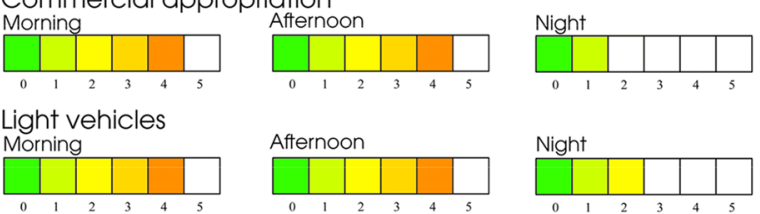

Light verning

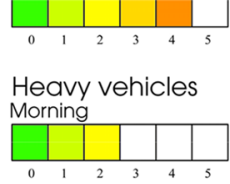

Afternoon
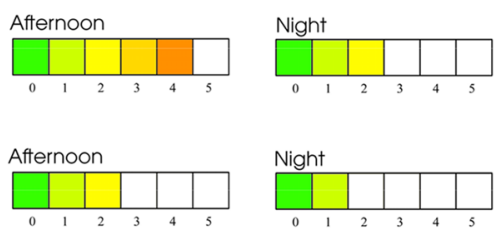

Tourist appropriation

Morning
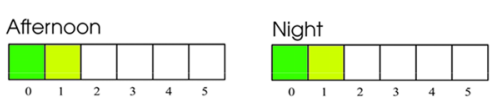

Fig. 11 Guide sheets for Leonardo Malcher area. Source Medeiros [39]

buses, bicycles, motorcycles)-morning (medium/ heavy); afternoon (medium/heavy); night (low/low), (10) Heavy Vehicles (buses, trucks) — morning (low/low); afternoon (low/low); night (low/low), (11) Tourist Appropriation-medium to high (Fig. 13).

After this survey, it is possible to understand each lot and their special vocations. Therefore, the chosen terrain vagues are (numbered and highlighted in Fig. 14):
1. The large area on Leonardo Malcher Avenue, partially occupied as a parking lot for SEBRAE.

2. The vacant lot between Símon Bolívar Street and Leonardo Malcher Avenue, neighborly two residential buildings.

3. The small terrain vague that belongs to IEA on Símon Bolívar Street.

4. Terrain vague (governmental lot) on 10 de Julho Street. 


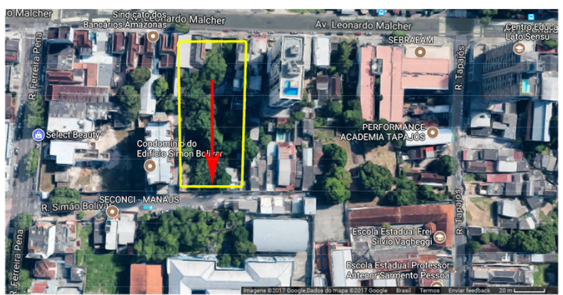

Reference: Símon Bolívar St.

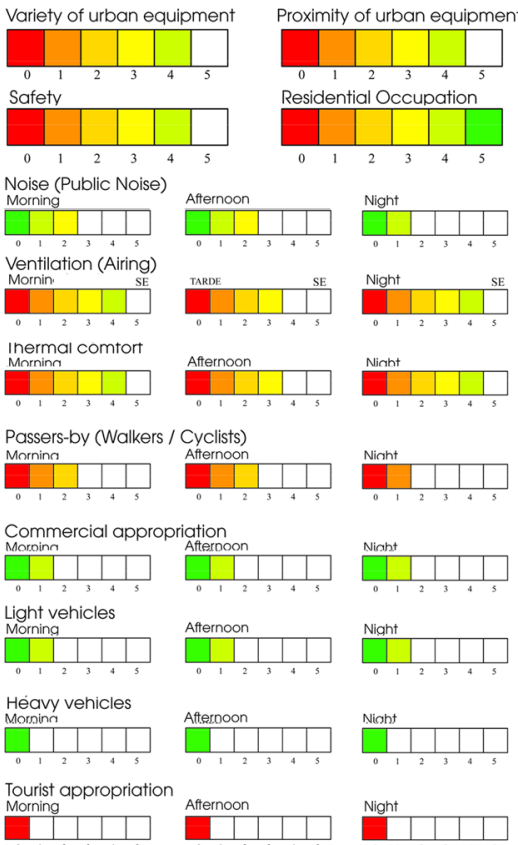

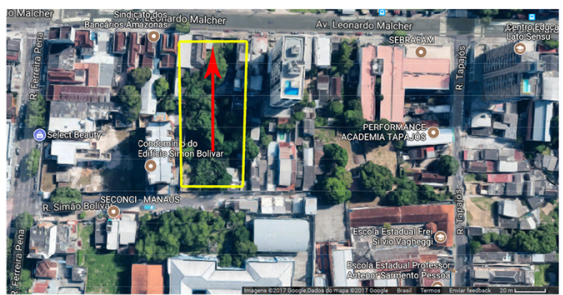

Reference: A. Leonardo Malcher

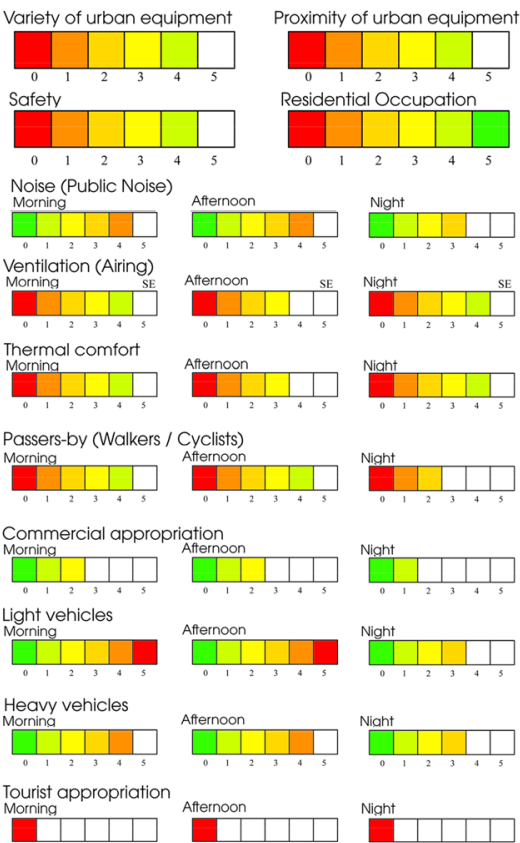

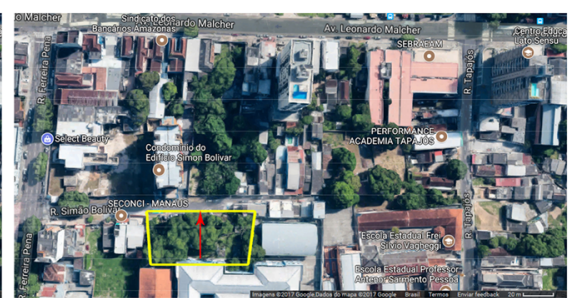

Reference: Símon Bolívar St.

Variety of urban equipment Proximity of urban equipment

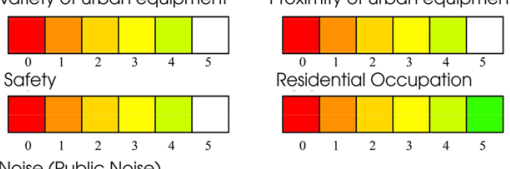

Noise (Public Noise)

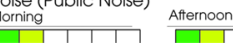

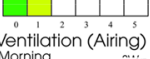

Morning (Airing) Afternoon

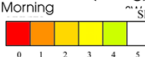

Thermal comfort

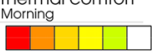

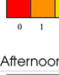

Afternoon
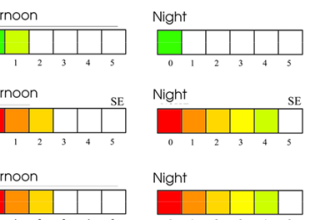

Passers-by (Walkers / Cyclists)

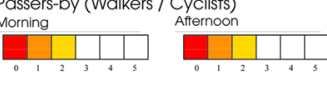

Commercial appropriation
Mfternoon
Morning

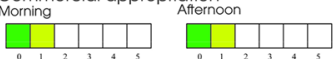

Night
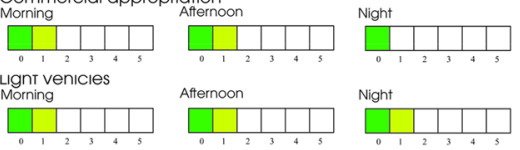

Heavy vehicles
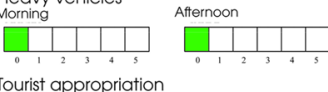

Night

tourist appropriation
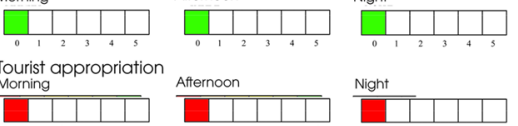

Fig. 12 Guide sheets for Leonardo Malcher/Símon Bolívar area. Source Medeiros [39]

5. Igarapé de São Vicente (São Vicente small river course).

6. The area partially occupied as a parking lot (legally a vacant land) on Getúlio Vargas Avenue.

7. The vacant land (legally) on Getúlio Vargas Avenue and Monsenhor Coutinho Street.

These seven lots will receive a special attention on the following urban proposals. Section 5 will highlight each one of the urban planning ideas.

\subsection{The legal challenges of occupation of vacant lots}

Legally, many of the terrain vagues of Downtown Manaus have law and legal restrictions (Sect. 4 mentions the registration in the Municipality Active Debt [38]), so to detach the architecture from the lot may be the best solution to dwell of those areas. For a legal occupation of those lots, it is possible to use two different law methodologies: the Concession of the Real Right of Use (CDRU - in Portuguese: concessão de direito real de uso) [40] and the Concession of
Special Use for Housing Purposes (CUEM-in Portuguese: concessão de uso especial para fins de moradia) [40].

Both legal instruments permit the use of terrain vagues with no intention of land property. CDRU points for a commercial, educational, cultural and leisure usage, while CUEM is a specific tool for housing purposes. Since most property legal restrictions in Brazil are proceedings in secret of justice, it is not possible to list all restrictions of each lot, but that will not muddle the application of CDRU and CUEM since both tools do not change the property ownership (legally, administratively or even de facto). Their only goal is the usufruct, the use and the fruition of lots [40].

Therefore, the occupation of the terrain vagues of the Center of Manaus follows the Brazilian's National Policy of Urban Development [41], which indicates the objectives of action and the prediction of popular participation to build a better city. Manaus's Municipal Master Plan [42] must use legal instruments to combat the speculation of underutilized properties and distribute 


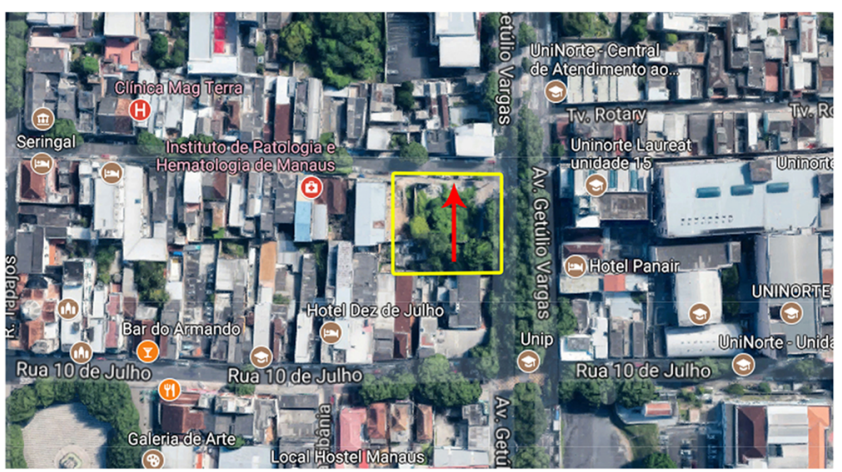

Reference: Monsenhor Coutinho St.

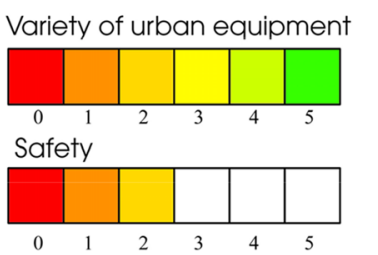

Proximity of urban equipment

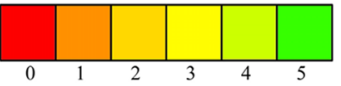

Residential Occupation

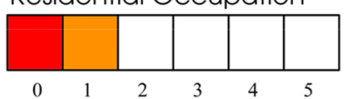

Noise (Public Noise) Mornina

Afternoon
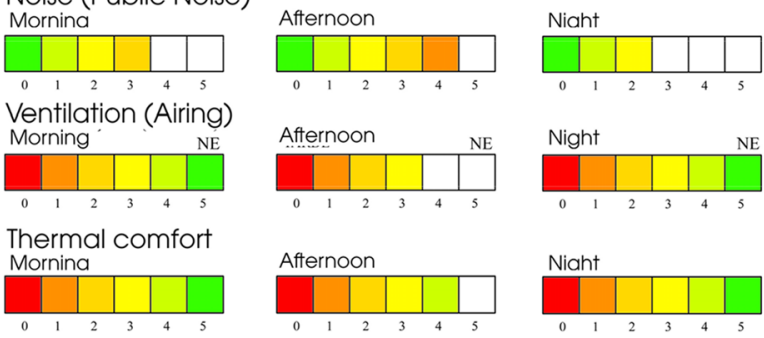

Passers-by (Walkers / Cyclists) Mornino
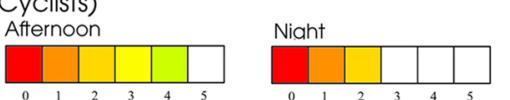

Commercial appropriation
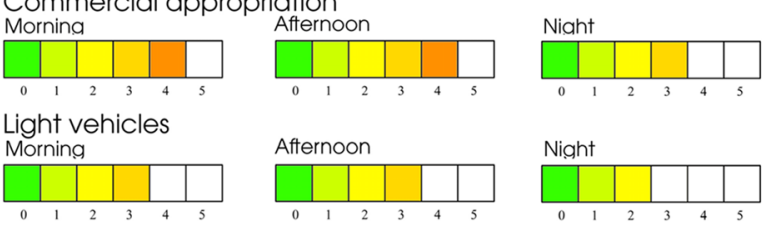

Light vehicles

\section{Morning}
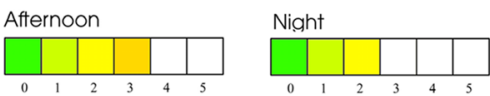

Heavy vehicles
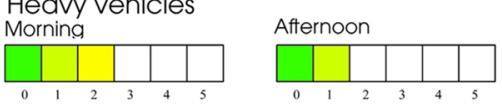

Tourist appropriation Morning
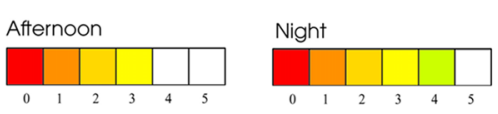

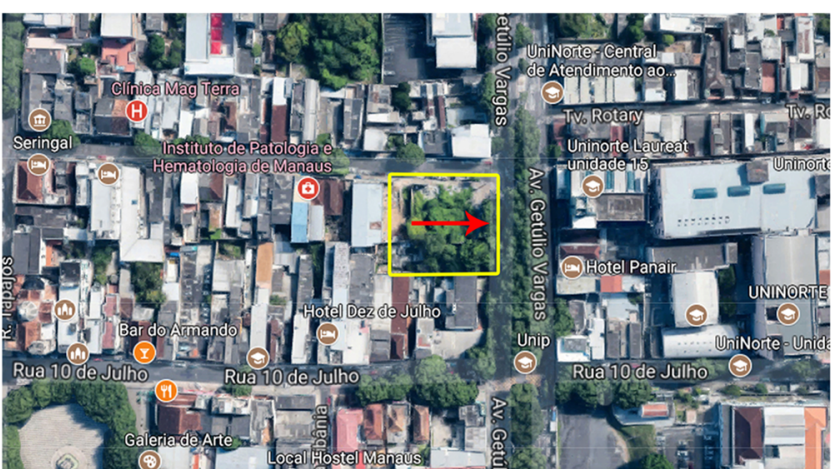

\section{Reference: A. Getúlio Vargas}

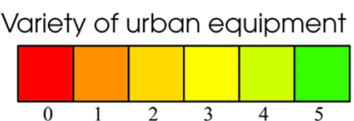

Safety
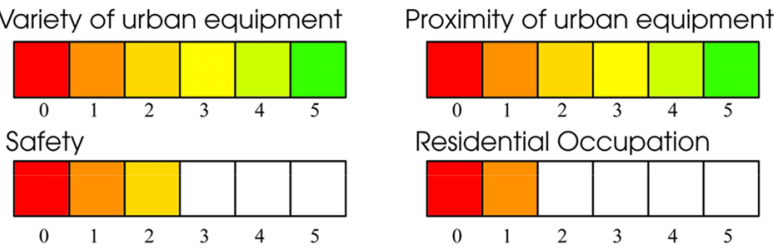

Residential Occupation

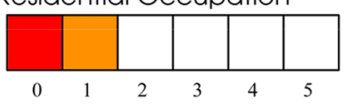

Noise (Public Noise) Mornina

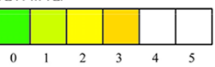

Ventilation (Airing)

Morning
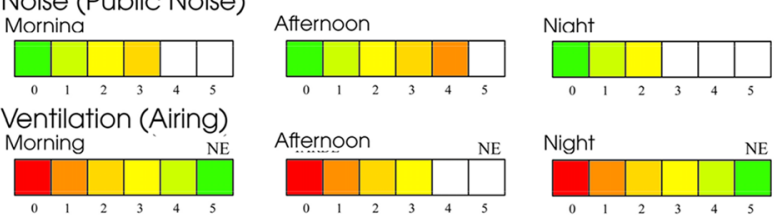

Thermal comfort

Mornina
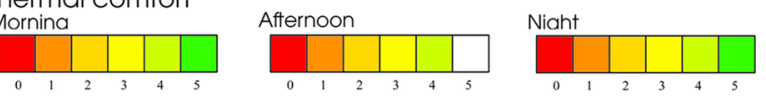

Passers-by (Walkers / Cyclists)
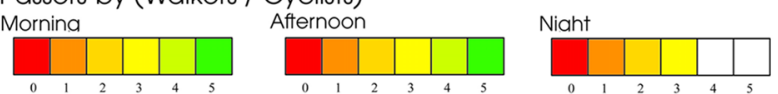

Commercial appropriation
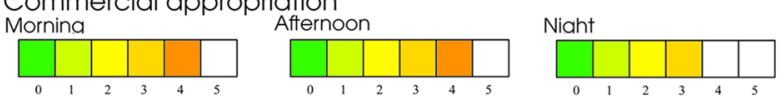

Light vehicles

Morning
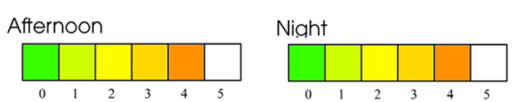

Heavy vehicles
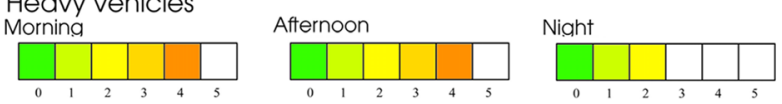

Tourist appropriation Morning
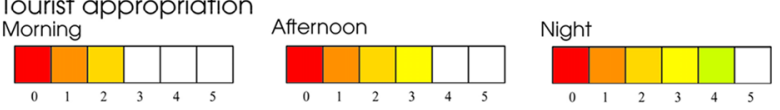

Fig. 13 Guide sheets for Monsenhor Coutinho area. Source Medeiros [39]

the benefits of the urbanization process in order to meet collective interests. Consequently, the occupation of empty lots through a methodology of rapid occupation is quite pertinent and salutary within these parameters, in especial if the occupation of lots goals is housing propositions.

SN Applied Sciences

\section{Pod Houses project: sustainable residential (re) occupation}

The present study aimed to point out solutions to urban acupuncture for the Center of Manaus. The focus here is to propose reliable operations (urban acupuncture), to promote revitalization with the support of the agglutination 

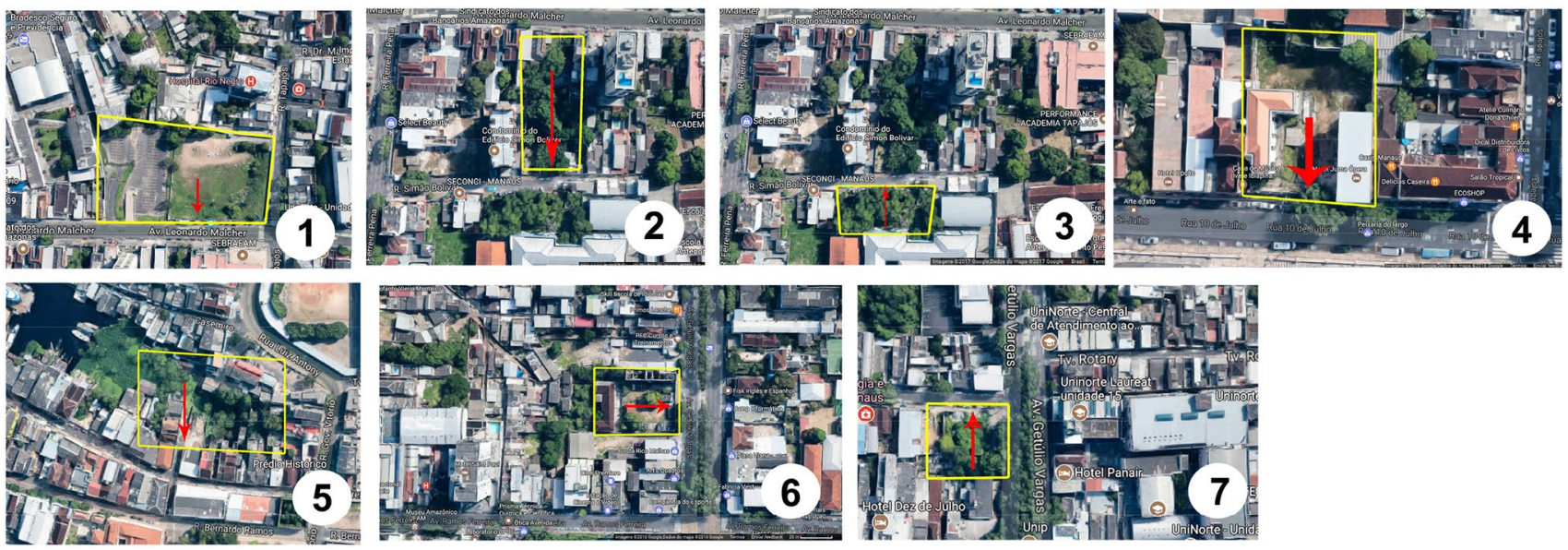

Fig. 14 Terrain vagues selected for this work. Source Medeiros [39]

activities of commerce and services, integrating them with circulation, leisure and housing, as proposed by Jacobs [27]. Even though the main objective of this project is the housing aspect, for the sake of livability and diversity, there is a mixture of different buildings and public spaces, as a way to propitiate a sensation of safety, and public contact.

The project follows the example of Jaime Lerner's proposals for Curitiba [37, 43]; it is far more effective to work with small-scale interventions that cost insignificant amounts of money and widely raise the image quality of the city [37]. As Macedo [43] points, only by using the continued city planning, it is possible to make a city more sustainable. Curitiba only turned into an example of the sustainable city after five decades of continuous work; thus, the image of the city also improved due to an intense and systemized effort that would reach its peak during Jaime Lerner administration [36]. The urban acupuncture of Curitiba is one of the good examples of how small changes in the urban texture can make a massive difference within the city.

By mixing architectural and urban approaches, it was possible to propose a solution that would not harm the environment or the legislation. For residential occupation, the concept of metabolism (Japanese urban and architectural ideas, which see spaces like living, growthenhancing organisms [44]), the concept in which the city is a living and changing organism, was the theoretical basis of design.

The name "Pod Houses" comes from a biological comparison between the houses and a butterfly's pupa: It grows to accommodate the growing organism [39]. The project aims to create a basic module capable of being multiplied and linked together to form an agglutination of blocks [39]. This project relates to the three pillars of sustainable development: fair housing to low-income communities; avoidance of urban sprawl; and mesological architecture integrated with the environment [39].

The Pod House's modules can be constructed using steel frame or wooden balloon frame. Both construction methodologies on houses aim the design for disassembly. (Figure 15 shows the structure.) This approach allows that people own the houses but not own the lots where they are located, which was a preoccupation pointed in Sect. 6 . All houses can be taken apart and pull together on other lots, making it possible that inhabitants move within other terrain vagues [39].

Figure 14 shows a schematic drawing of the Pod House module. Reading: 1 -thermo-acoustic sandwich aluminum tiles, 2-thermally insulated wood lining, 3-rainwater chute, 4-plumbing to collect rainwater,

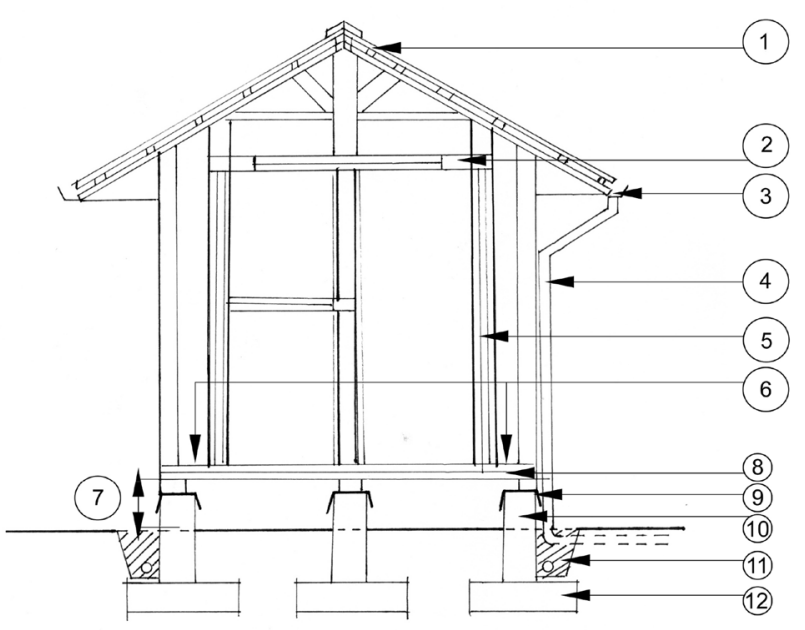

Fig. 15 Pod House schematic disposition. Source Medeiros [11] 
5-double-sided frame wall, 6-bungalow structure balcony, 7-house-ground separation, 8-thermally insulated wood flooring, 9-metallic protection of the wooden structure, 10-wood pilot, 11-rainwater collection section, 12-concrete sabot.

There are two basic Pod House's modules: Type A (Fig. 16) and Type B (Fig. 17). Type A (Fig. 16) modules have a larger balcony structure to adapt the mixed use, such as commercial use. Type B (Fig. 17) modules are residentialfocused modules. Both modules reserve a top area named "naked space." The conceptual basis is Kazuo Shinohara's third style, represented by the Umbrella House (1963) where there is the interpretation of this naked space in which spatial versatility makes any space a room [39]. The flexibility sought in this project converges to the idea of "anti-space" or "naked space," demonstrating the possibility
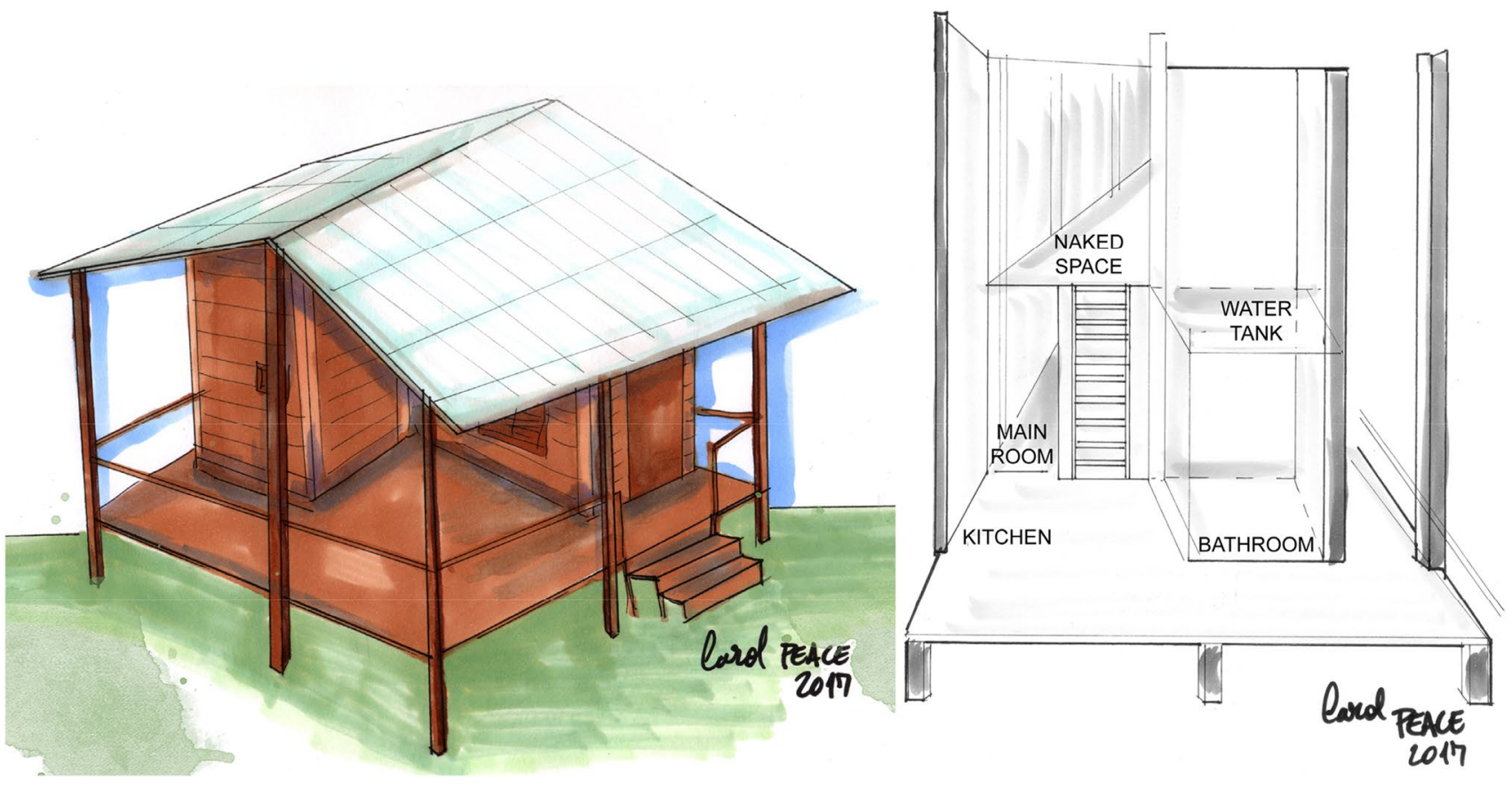

Fig. 16 Pod House Type A panorama and inside view. Source Medeiros [39]
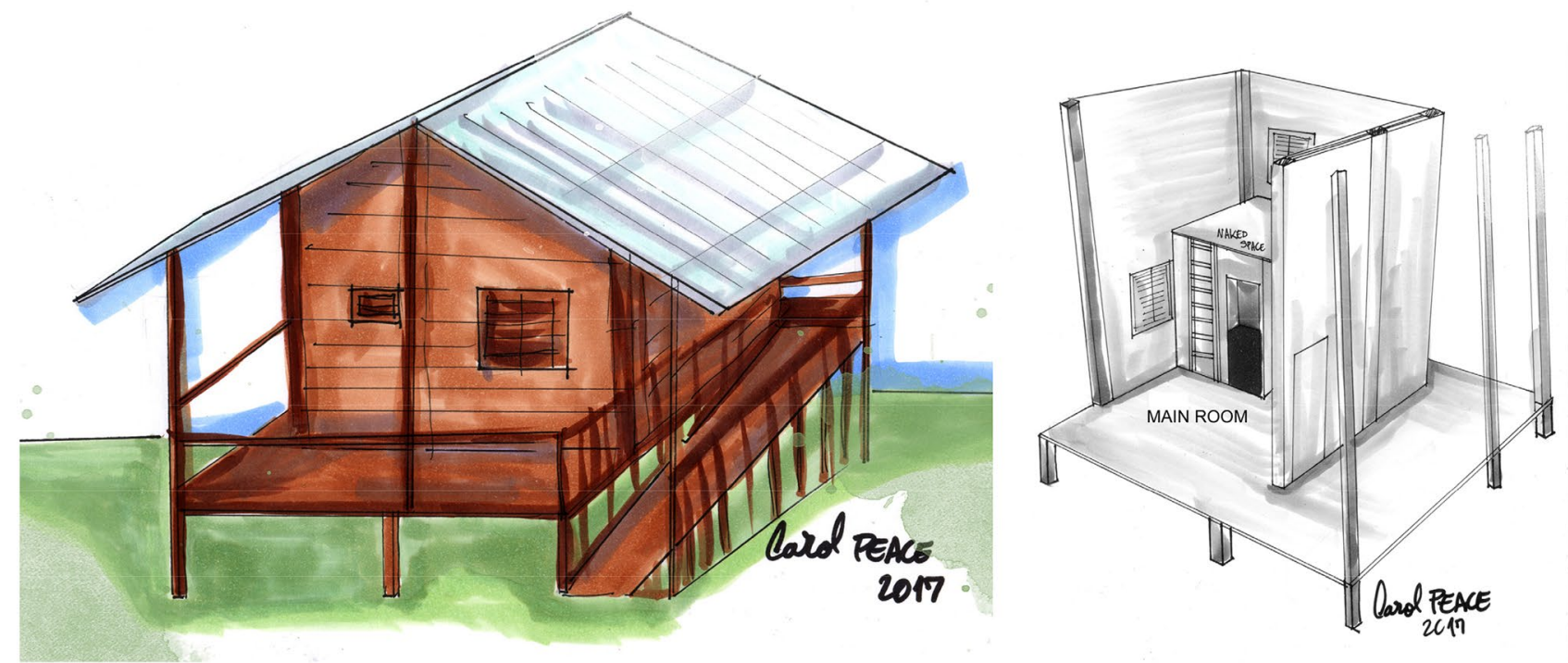

Fig. 17 Pod House Type B panorama and inside view. Source Medeiros [39]

\section{SN Applied Sciences}


that emptiness is a space to live with flexibility and versatility [39], much like the Amazon's version of balconies named "Girau" — a space where people can perform everyday duties, sleep, welcome guests and even use as a commercial spot [39].

The Pod Houses also aim for accessibility providing ramps and the possibility of remodeling, which can help people adapt their homes for their needs, using the different architecture projects offered. This is a ready-toassemble system where anyone can follow the project's basic instructions to construct a house. For that matter, the projects aims to make structures that are easy to replicate on larger scale. Figure 18 explains some of the stages for a Pod House assembly.

Figure 18 shows a brief overview of a Pod House production and assembly. First, we need certified wood for the construction. Later, there is the processing of wood and of steel frame for parts production. Each part/piece receives a number to make assembly easier. Then, we deliver the Pod House to the construction site. Local workforce can carry each one of these stages, making the whole process a lot easier. A simple pulley/tally system can help on the final assembly. A small truck can deliver the whole project.

There is no intention on permanently living within these areas; the only intention here is to bring people eyes to spaces where there are housing and the necessity of security. Jacobs [27] tells us that "the public eye" is the main reason we fell safe on populous neighborhoods, places where there are children playing on sidewalks and where there are people we know. The vilas firm these relations since they are often composed by families or by close friends that chose to live close each other. These relations come from the oldest times, since Manaus was only a small village [29, 33]. Vilas are the oldest form of occupation of the district. Vilas are small residential areas where friends and families live, often sharing public spaces while living on different houses. The use of a Portuguese word to refer to these areas is because these small neighborhoods do not have an English word that correctly fits this description. They are not neighborhoods because they are too small to fit such description and they are not villages since they are not small cities. They should not be confused with "villas" since they are not big country houses. That is why the word "vilas" is the preferred terminology for them.

After the project's brief explanation, now it is time to trace an overview of the housing system. The Pod Houses use basic modules to establish residential vilas, and all of them are mixed-use urban structures that aim to provide a place where the inhabitants can establish market places. All modular structure follows the logic of simple replication, linked to the idea of showing that modules that can fit the terrain vagues studied [39].

Jacobs tells more about the city diversity. The mixed uses within areas help generate multiplicity within a city [27]. The combination of a mixture of uses, neighborhoods and parks can bring a sensation of safety and public contact. The commercial choices, the cultural interest, diversity, the convenience and the points of interest can make districts mode livable. Jacobs points four conditions to make urban spaces livable and diverse: (1) Buildings and public spaces should serve more than one primary function; (2) blocks should be short and small; (3) mingle different buildings; and (4) places should have a dense concentration of people, especially by using urban spaces for housing, even when planning mixed-use areas [27]. Those guidelines served as a framework for this project.

A very important point of this project is that all houses have planned areas for possible remodeling, extensions and for the commercial use. The vilas on downtown are often mixed-use areas; therefore, people use the space

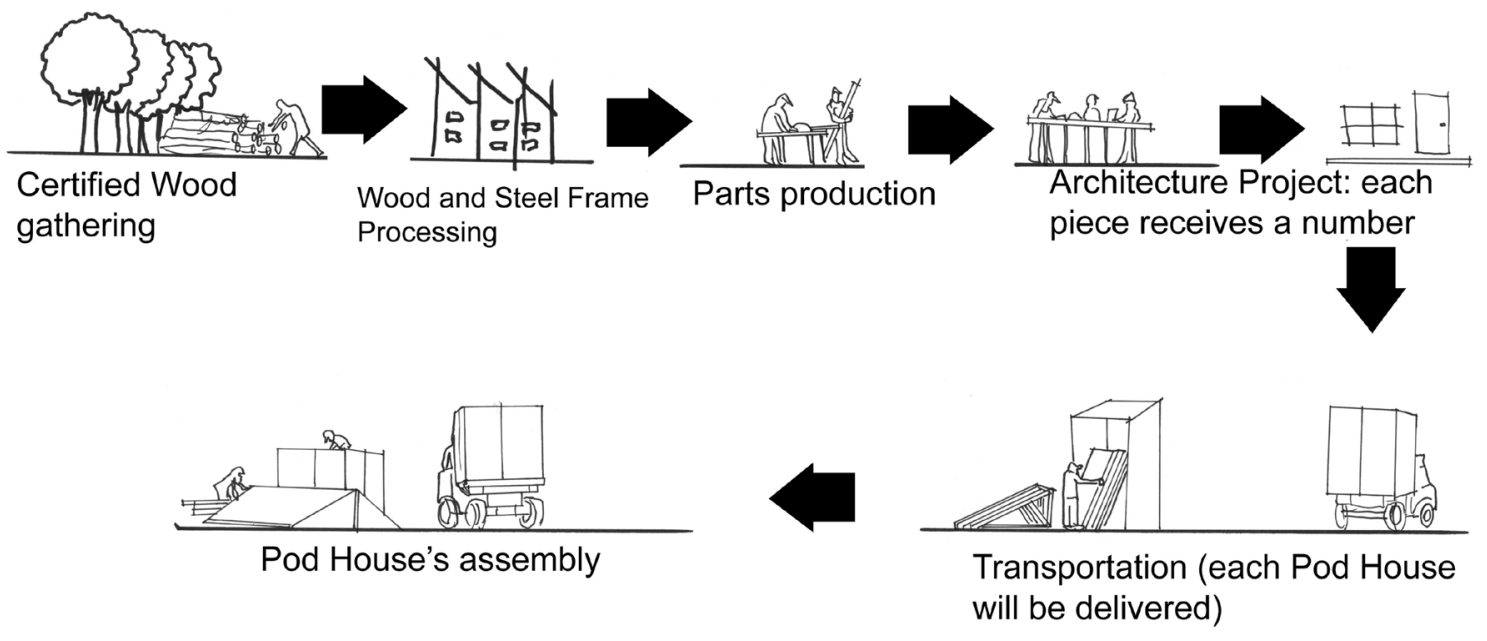

Fig. 18 Pod House production stages and assembly stages. Source Medeiros [39] 
for housing and for local stores, for example bodegas and beauty parlors. That is the reason why the proposed urban planning does not contemplate a commercial use area since this neighborhood already has a vast and strong merchant zone.

As Alfadala and Furlan wrote, the New Urbanism focuses on human-scale urban design [45]. Consequently, the principles related to the New Urbanism are connectivity, walkability, mixed use, urban design, traditional neighborhood structure, sustainability and quality of life [45]. The vilas structures maintain all those characteristics plus Jane Jacobs proposed criteria for building cities that are more diverse. Even if the solutions proposed may look like a low-density path, it is important to remember Ahmed studies [14]. Ahmed points that the provision of utilities and amenities within neighborhoods ought to be the focus on urban planning, where accessibility and integration will function well when the urban planner does not impose heavy densities to areas which are already populated. Regeneration strategies should focus on communities' welfare rather than on making places over inhabited [14]. The vilas also avoid discriminatory zoning and propose porous boundaries that provide a space for communicative and collaborative participation [6].

The urban vilas proposed for this project are marked on the next two images: Fig. 19-(1) Leonardo Malcher Vila, (3) Simon Bolívar Vila; and Fig. 20-(1) Getúlio Vargas Vila. Figure 19 also illustrates two other locations: (2) Leonardo Malcher Piazza and (4) Students' Residence. All those vilas have a connection to their green areas, making possible that their inhabitants use the spaces for urban agriculture [46]. These green spaces that surround and in between the houses aim to contribute to the urban ecology and biodiversity [46]. The Pod Houses relate to the green spaces as part of their possibility of growth [39].

The housing solutions aim to repopulate these areas, since they are spaces where it is desirable to have more people living. Since all the lots have some kind of legal issue that may (or may not) be solved during the time, people are living within this spaces. It is impossible to think on a solution where the housing density is higher than ten people per $1 \mathrm{~m}^{2}$, since that would demand the construction of buildings (which would invalidate the disclosure of movable residences). So all the houses are movable and affordable, in attention to the public challenges inherent to all those terrain vagues.

This urban solution differs from urban projects ongoing in Manaus, like PROSAMIM (Manaus Igarapés' Social and Environmental Program). PROSAMIM urban planning mainly aims to construct small buildings (three to five floors each) on areas where people lived within the river course on palafitas (slits or blockhouses in English) [47]. There is substantial change on people's life since the buildings only aim to serve as storage place and not as a home for all those individuals [47]. For that matter, the Pod Houses project aims to keep people close to their own understanding of what dwelling on Amazonas really is about, vicinities, smaller houses and a very strong feeling
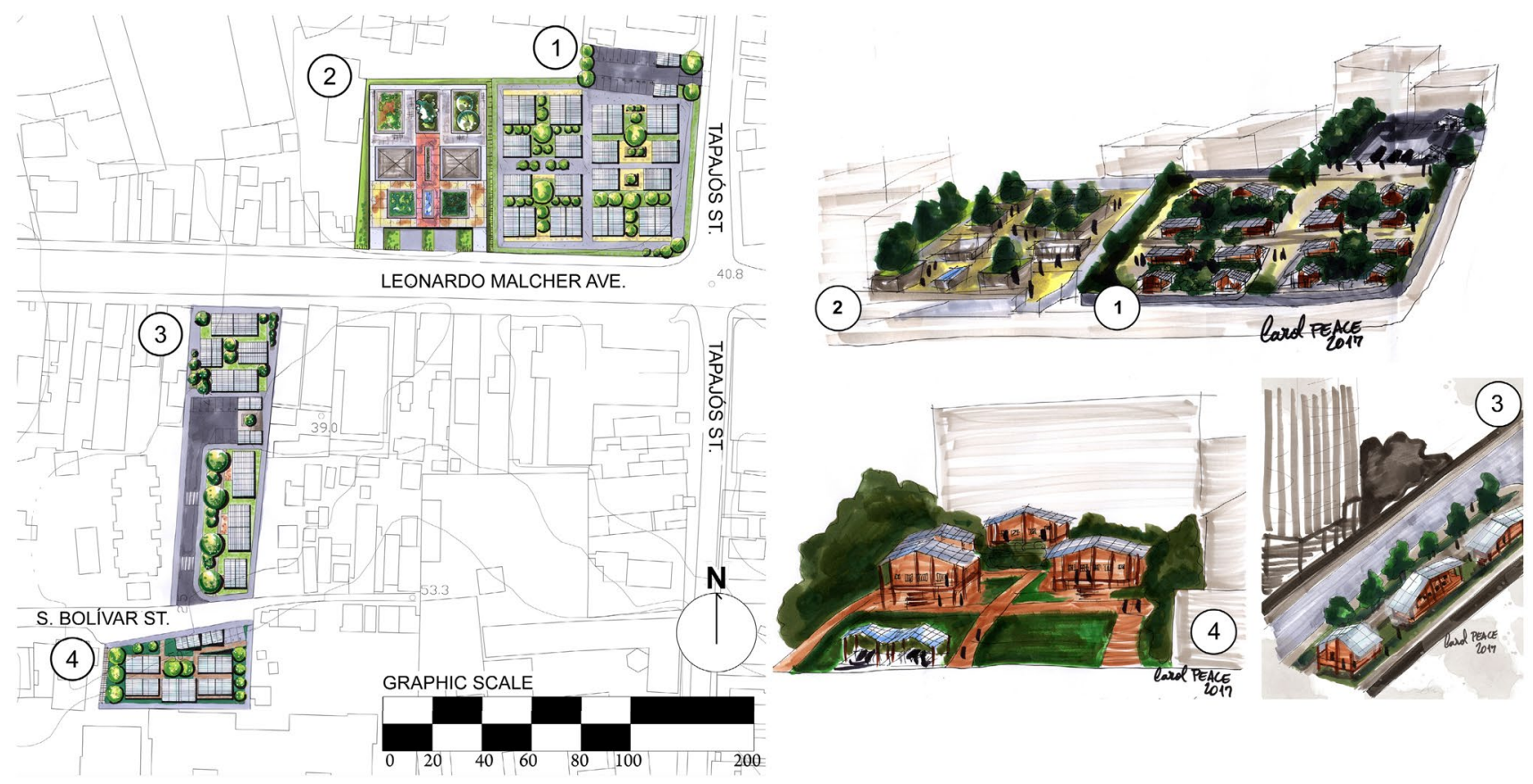

Fig. 19 Urban level: Pod Houses. Source Medeiros [39]

\section{SN Applied Sciences}



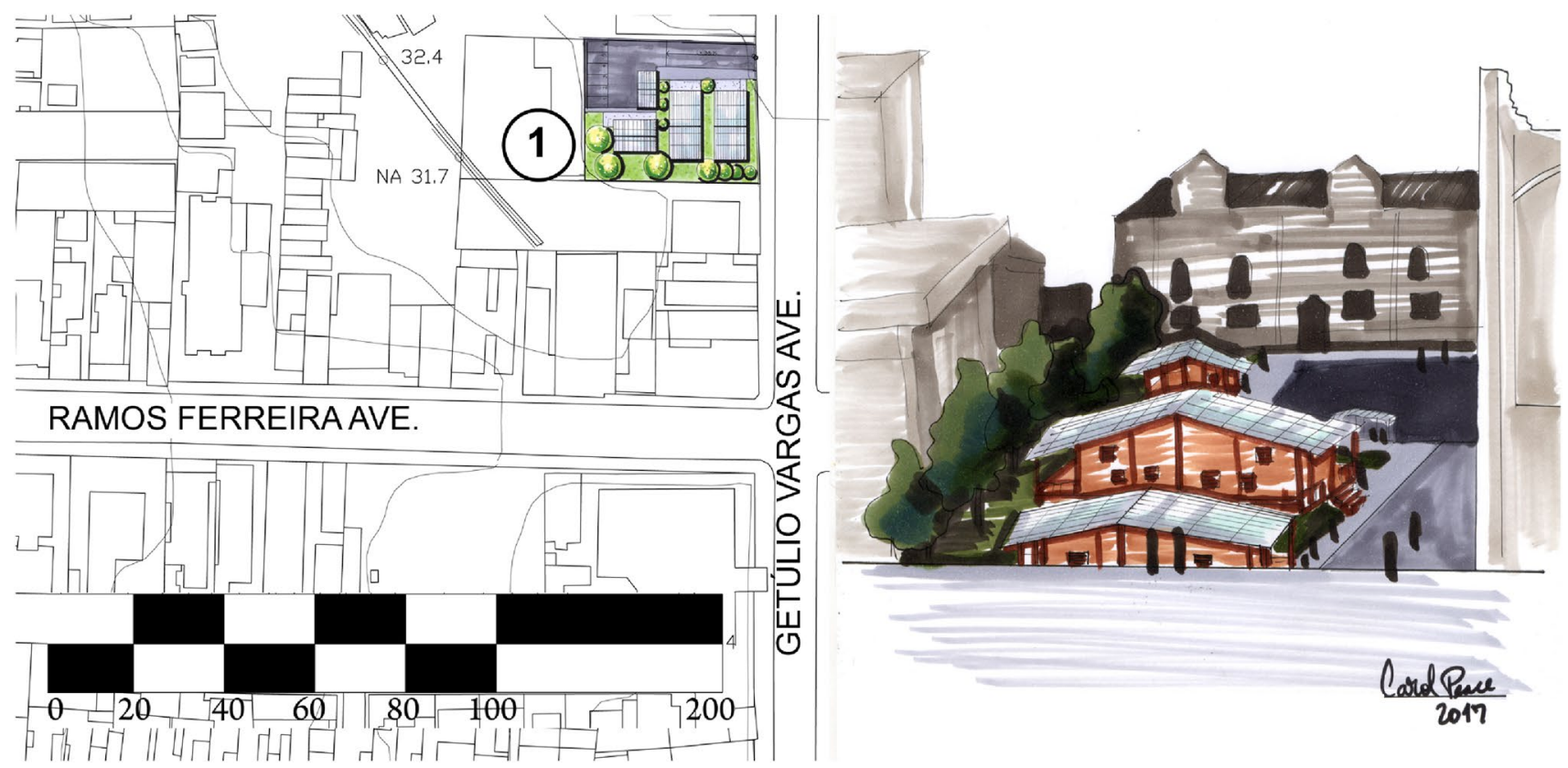

Fig. 20 Urban level: Pod Houses. Source Medeiros [39]

of belonging as the houses take many similarities from the riverside's way of life.

\subsection{Beyond Pod Houses: urban planning and the right to the city}

However, the main project considers public areas and gives new perspectives of intervention that provide abandoned spaces. The designed public spaces are a plaza (piazza), a Cyclist Support Square and São Vicente Bridge Park. There is also a hostel suggestion (The Pod Hostel) that gathers as a servicing proposition. The Students' Residence is also a public structure due to its relation to Institute of Education of Amazonas (IEA). While the housing propositions turn to be transitional propositions since the houses are movable, most of the public structures propositions have a permanent aspect, due to the necessity of robust structures. The Cyclist Support Square, the Students' Residence and the Pod Hostel are movable, due to using the same wooden frame structure as the housing propositions.

However, landscaping planning has to understand spatial-temporal variations, especially when designing a livable city with environmental quality and a worry about human well-being [46]. The urban ecosystem includes the ecological services, the urban vegetation, the urban agriculture and even the flood protection [46]. All those aspects are primordial to Manaus, a city cut by many rivers and their tributaries, and therefore need to protect the riparian forest and guarantee the protection of the water basin. Fainstein and DeFilippis point that a holistic vision toward a sustainable city planning is the best way to ensure the economic development that does not forget the environment and the people [6]. It may seem impossible that a city can be green, profitable and fair, but we will only know it for real if we try our best to overcome the resources conflicts, the property conflicts and the development conflicts. Fainstein and DeFilippis add that sustainability is a useful concept for the longterm goal of creating cities in balance with nature [6]. The sustainable practices are a voluntary choice. That is why it is important to avoid the modern-day Narcissus act where people see nature only as a mirror of human values and futuristic aesthetics [6].

Urban resilience is also a very important aspect on city planning. Meerow, Newell and Stults mention that urban resilience refers to the ability of an urban system to adapt when facing a disturbance and to "adapt to change and to quickly transform systems that limit current or future adaptive capacity" [48]. To Bertilsson et al., the "combination of climate change and increasing urbanization brings great challenges to planning and managing cities for sustainability" [49]; therefore, there is a need to think about integrated systems that manage to absorb changes and that can dynamically accept different equilibrium possibilities (or maintain ecological resilience). All planning should bring porous contestable limits between mutually dependent forces (the economy, society and nature, keeping the flexible balance) [6]. So, the projects here presented are not static; they all have a 
very holistic vision that the cities change, and therefore, parks and green areas are also subject of change.

It is also very important to map urban ecosystems aiming to provide outdoor recreation, "such as jogging, bike riding, picnicking, observing flora and fauna or simply enjoying the nature" [50]. A diverse area gathers many different people, however, to design a landscape for diversity we need to classify and evaluate, to establish the criteria, and to propose the design solutions [37]. Section 4 has the evaluation and classification of the areas, but there is still a need to establish the criteria for the solutions. The first principle is to use vegetation from Amazon region, avoiding the use of important plants. The second principle is to develop structures that can be modified and remodeled. The third principle is that urban parks have to have their own source of income. The fourth principle is that the proposed solutions connect people to nature. The fifth principle is that the solutions do not change the soil's contour, aiming to solutions that do not affect the natural landscapes, or to present solutions that do not cause heavy soil movement.

The figure shows the urban planning of Leonardo Malcher Piazza as well as its panorama view. The first structure is the Leonardo Malcher Piazza (Fig. 21), a cultural and leisure area that provides a parking lot on its underground as a way to maintain the plaza economically. The Piazza is a garden for everyone on Leonardo Malcher Avenue, since there are many residential buildings and a great number of dwellings that can enjoy the Piazza. This idea is similar to what Burle Marx intended on Gustavo Capanema's Palace, for example. This project is also a terrace garden easily seen by the other buildings that surround the area. Leonardo Malcher Piazza is a public space, but it still maintains its relation to SEBRAE, since the underground parking lot will still attend the necessities for the area.

The figure shows the urban planning of Pod Hostel and the Cyclist Support Square as well as the sections for each project. The next area is the Cyclist Support Square. Several urban projects in Manaus aim to make the city friendlier to its cyclists [11]. Due to this constant cyclist use, the Cyclist Support Square (Fig. 22, n. 2) is a proposition suiting the constant use of bicycles on the area, providing a bicycle rack and a bicycle rental point. The Pod Hostel (Fig. 22, n. 1) is a showcase for the project, providing rent rooms for people that want to understand the Pod Houses experience. The Pod Hostel takes place in front of Amazonas Theatre, one of the most iconic constructions of Manaus. The hostel can serve to the government as well, since it is located on a public area.

The Students' Residence (Fig. 23) aims to meet the needs of students of the Institute of Education of Amazonas (IEA) that come to study in Manaus but live on riverine areas or within the country side of Amazonas state and do not have another place to live by their school. This is a place where they can safely live for a short period (until they can find another place to live) or to live during the school year.

Finally, the idea of the park (Fig. 24) is on the bed of the Igarapé of São Vicente. The justification for presenting this type of concept is the existence of a terrain vague quite attached to the Amazonian biome: the terrain vagues over the water. This space is a permanent protection zone; thus, a bridge that interconnects streets that stop at the edge of the lgarapé is a way to use this as a cultural zone. This area has a strong touristic appeal. A sustainable park would be a great achievement to Manaus as a way to show that vernacular architecture is essential cultural heritage to the city [39].

The figure shows the urban planning of São Vicente Bridge Park as well as its panorama view. São Vicente Bridge Park can unify two points that already share an urban relation. People from each side often use boats to travel to each side of the basin, and the Bridge Park would only intensify those relations, connecting two

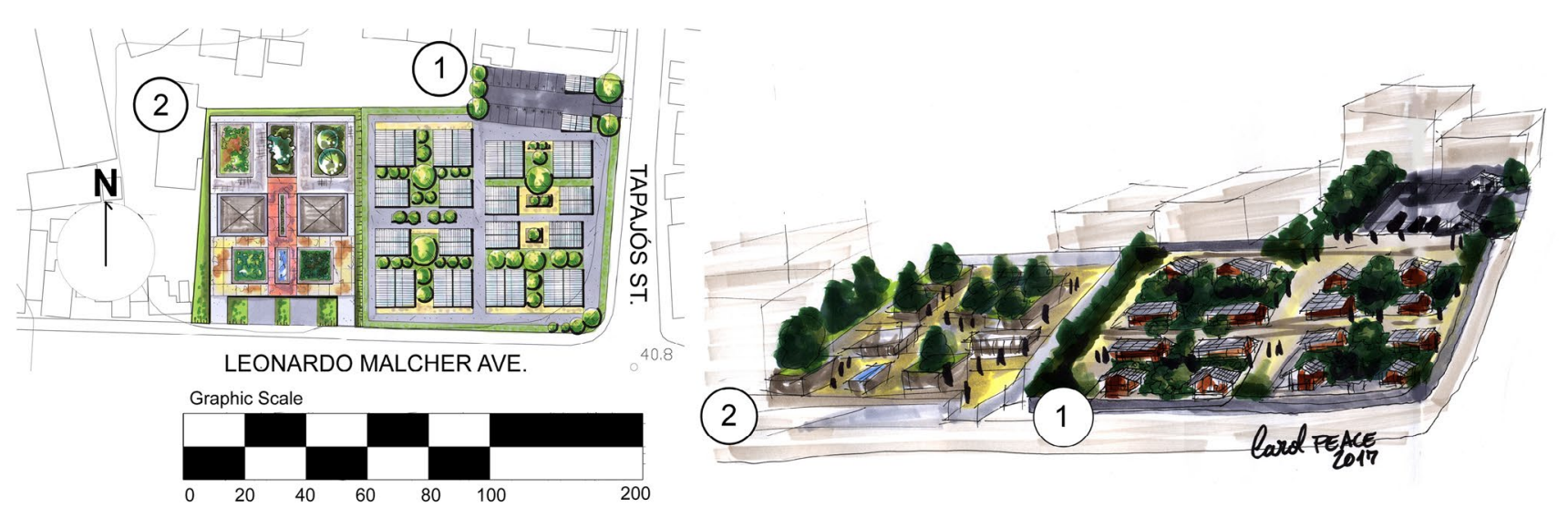

Fig. 21 Leonardo Malcher Piazza. Source Medeiros [39] 
Fig. 22 Pod Hostel and the Cyclist Support Square. Source Medeiros [39]
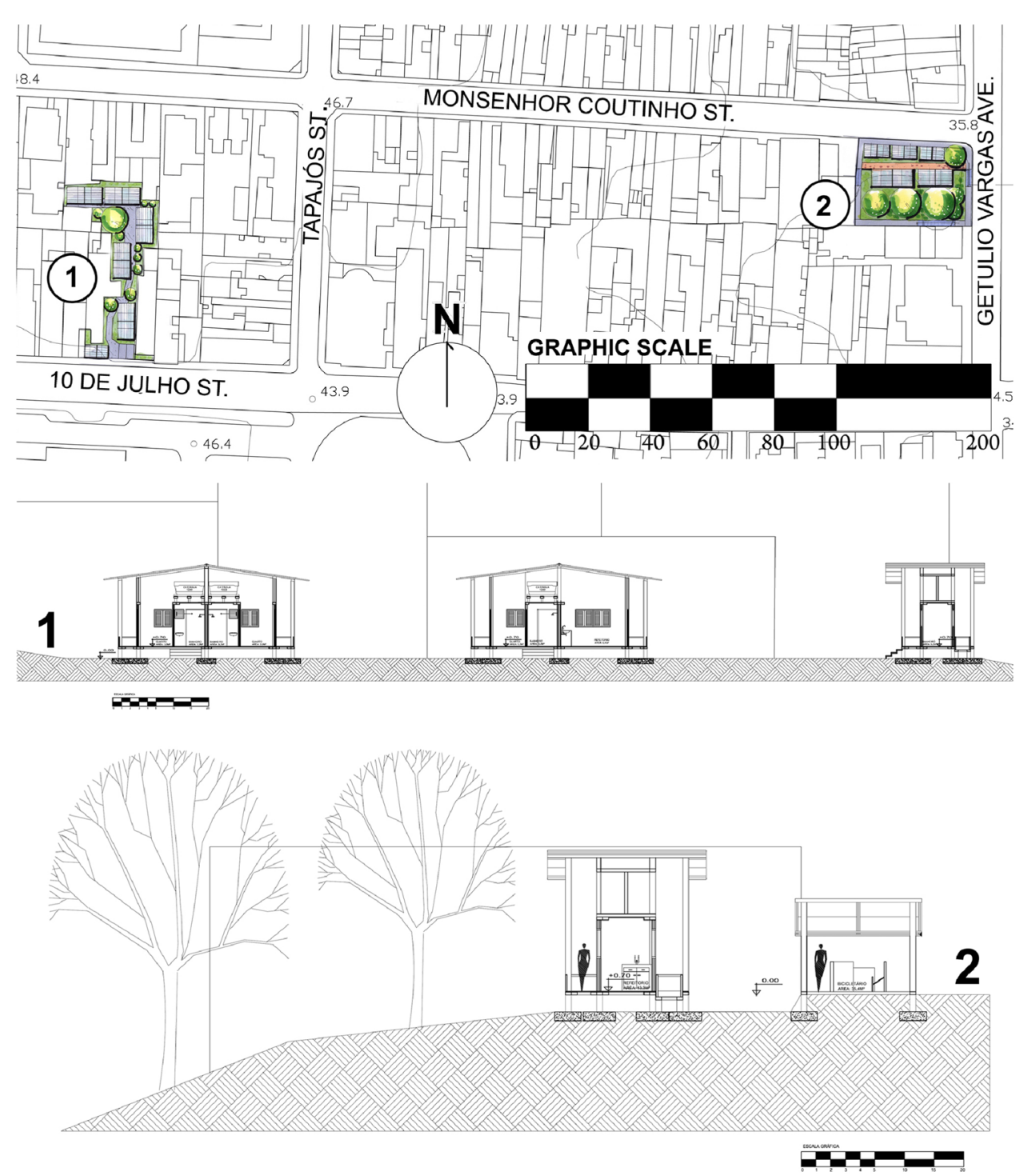

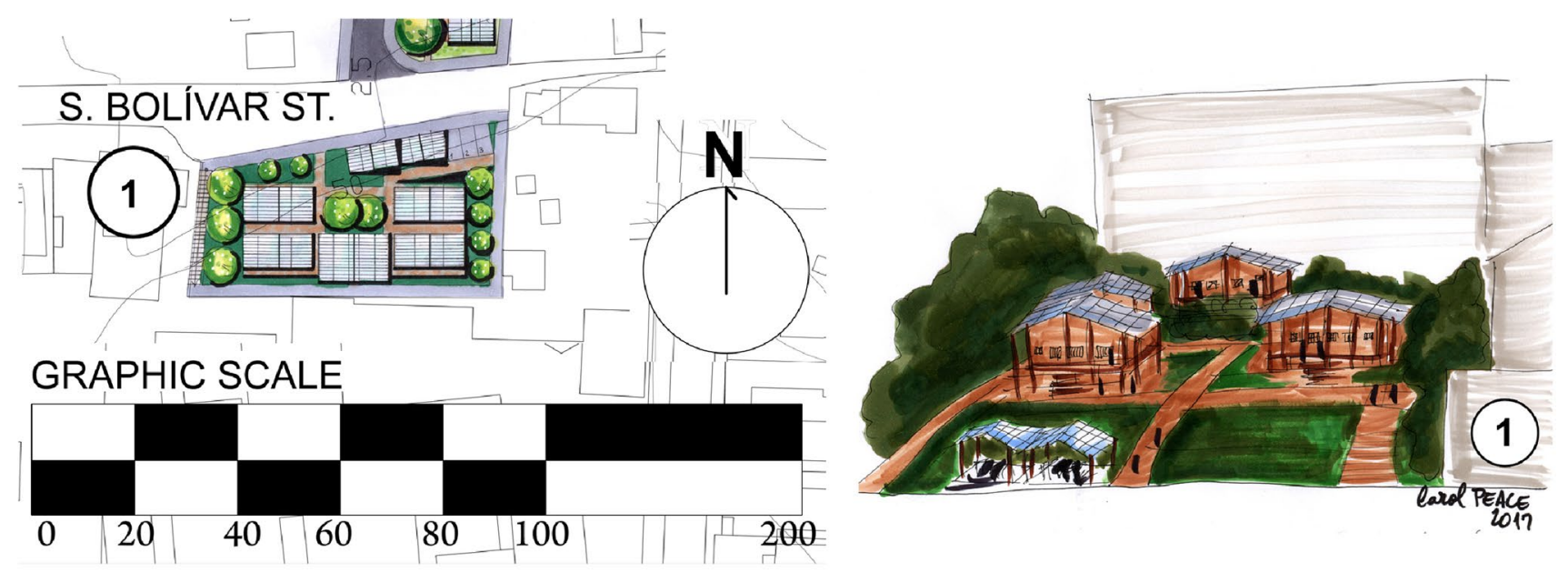

Fig. 23 Students' Residence. Source Medeiros [39] 

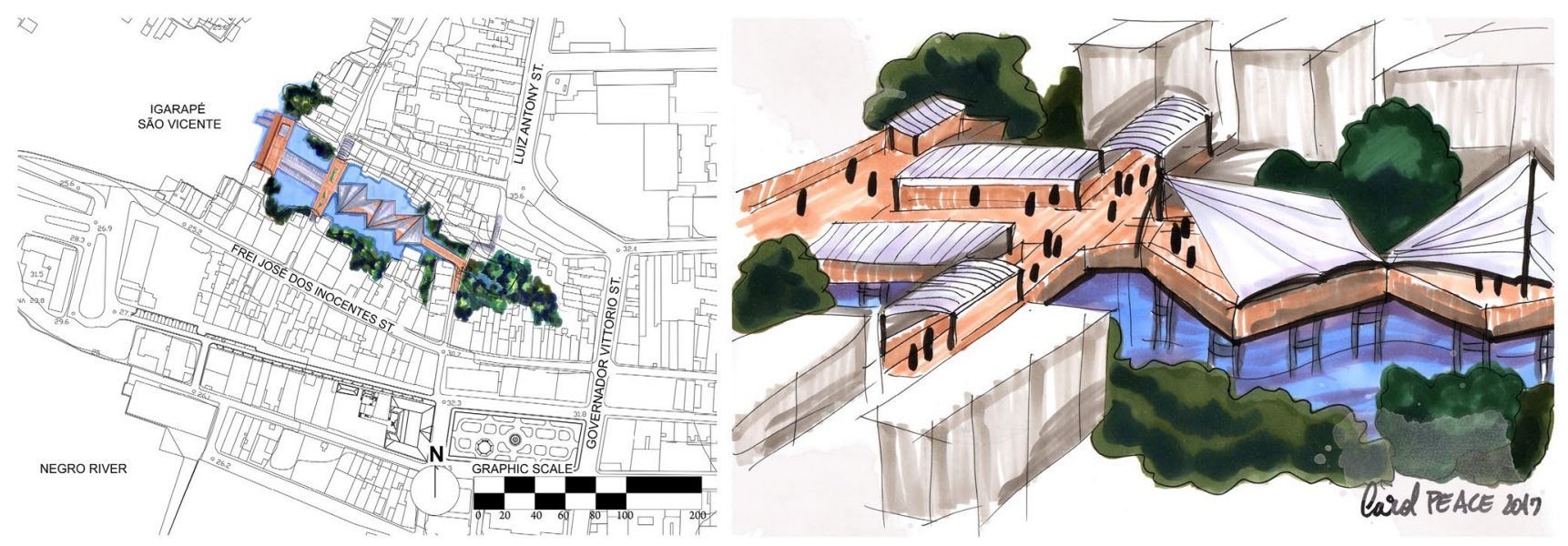

Fig. 24 São Vicente Bridge Park. Source Medeiros [39]

streets currently separated by the watercourse. The perspective drawing (Fig. 24) shows that the project aims to connect and simplify the urban walkthrough. Some of the public spaces proposed are abiding areas but (e.g., São Vicente Bridge Park and Leonardo Malcher Piazza), even if they got permanent structures, it is possible to remodel them. Remodeling structures and modifying them are also important to keep the areas alive and prosperous [27].

\section{Conclusions, contributions and implications of this research}

This research still holds many possibilities for the future study of Manaus' vacant lots (even the ones that do not configure terrain vagues). Downtown Manaus still holds the potential of uses that do not limit commercial and administrative routines. With more study and further government preoccupation, it will be possible to achieve great deeds for this area. It is vital that political powers employ laws and regulations to reoccupy abandoned areas, especially with housing projects that aim to satisfy less fortunate people. All those actions can stop the urban sprawl from growing further into the forest and help on the achievement of a sustainable city.

The Pod House structure is very easy to assemble, and the urban project itself aims for the low cost, since local people can assemble, make and work with all structures proposed. Even if there is no governmental interest on the project, the private initiative is still a possibility for making Pod House project possible. However, the aim of this scientific research is to show that different approaches for urban planning are possible in Manaus, especially the ones that are far different from PROSAMIM projects, for example.

The implications for the private market relate to the growing market for pre-molded/prefab houses in Brazil.
There is the possibility to offer the Pod Houses on the market as a solution for fast occupation or even for transient occupation. Since the structure is very similar to what riverine people prefer to build, the housing solutions can also assist for Amazonas' countryside. There is also the possibility of application of the house projects on areas affected by disasters. All those options, however, demand new studies carried in the future by other researchers.

One of the limitations of this study due to time and resources was the application of these propositions on other areas in Manaus or even on Amazonas state as a whole. This investigation offers a framework for occupation of terrain vagues within Downtown Manaus applicable to future scientific researches.

As a final point, the Pod Houses project is just an example of what is possible to ensure by the proposition of affirmative public policies of recycling urbanized areas than just legislating to serve solely as jurisdictive walls to abbreviate human rights. The future of Manaus urban area depends on participatory and democratic management that provides a fertile ground for a sustainable approach to urban planning. As a result, this study points to the necessity of more research about sustainable uses and new propositions for Manaus urban planning.

Acknowledgements This work was partially funded by State of Amazonas Research Support Foundation-FAPEAM (Fundação de Amparo à Pesquisa do Estado do Amazonas), from 2015 until 2016.

\section{Compliance with ethical standards}

Conflict of interest The authors declare that they have no conflict of interest.

\section{SN Applied Sciences}




\section{References}

1. Villaça F (2001) Intra-urban space in Brazil. Studio Nobel: FAPESP: Licoln Institute, São Paulo

2. Gatica YC (2012) The commune of Santiago de Chile: a new residential option for the city. In: D'arc HR, Memoli M (eds) Urban interventions in Latin America: living in the center of cities. Editora SENAC, São Paulo

3. Hiernaux D (2012) The imaginary and the places in the reconquest of the historic center of Mexico City. In: D'arc HR, Memoli $M$ (eds) Urban interventions in Latin America: living in the center of cities. Editora SENAC, São Paulo

4. Barnett J (2018) The fractured metropolis. Routledge, Taylor \& Francis Group, New York

5. Rolnik R (2016) War of the Places: the colonization of land and housing in the bailout era. 1st edn. 2a re. Boitempo, São Paulo

6. Fainstein SS, DeFilippis J (2012) Readings in planning theorystudies in urban and social change. Wiley-Blackwell, West Sussex

7. Sarin M (1982/2019) Urban planning in the third world-the Chandigarh experience. Routledge, Taylor \& Francis Group, New York. ISBN 13: 978-0-429-34325-4 (ebk)

8. Frúgoli JRH (2012) Intervention in the central spaces of Brazilian cities—the case of São Paulo. In: D'arc HR, Memoli M (eds) Urban interventions in Latin America: living in the center of cities. Editora SENAC, São Paulo

9. Solá-Morales I (2009) Terrain Vague. In: Ábalos I (ed) Collection contemporary architecture compendiums. Editorial Gustavo Gili, Barcelona, pp 123-132

10. Solá-Morales I (1996) Present and future: architecture in cities. Congrés UIA, Barcelona

11. CESER. Requalification des friches urbaines: quelles perspectives en région Centre-Val de Loire? http://tiny.cc/kc1 pkz. Accessed 2 Jan 2019

12. Davies CS (1999) Derelict land. In: Environmental geology. Encyclopedia of Earth Science. Springer, Dordrecht

13. Lynch K (2005) Spoil: a deterioration analysis (Echar a perder: um análisis del deterioro). Glimi, Barcelona

14. Galal Ahmed K (2018) Sustainable urban regeneration strategies for deteriorated neighborhoods centers in UAE. In: Proceedings of 3rd international sustainable buildings symposium (ISBS 2017), pp 736-749. https://doi.org/10.1007/978-3-319-63709 $-9 \_56$

15. Barretto $M$ (2013) Urban revitalization, leisure and tourism. Rosa dos Ventos-Tourism and Hospitality. ISSN: 2178-9061

16. Oliveira CM (2016) Artificial cities: an exploratory study of the Porto Alegre 4D urban project. Braz J Organ Stud 3(1):77-99. https://doi.org/10.21583/2447-4851.rbeo.2016.v3n1.74. ISSN: 2447-4851

17. Zancheti S, Somekh N, Fregonezi B (2015) Urban revitalization in Brazil comparing six historical centers. HERITAGE FORUM: Built Environment and Sustainable Heritage. Belo Horizonte 8(1). ISSN 1982-9531

18. Maraschin C, Cabral GF (2014) The role of city center in contemporary urban structure-the case of Porto Alegre, Brazil. Arquiteturarevista Unisinos 10(2):59-69. https://doi. org/10.4013/arq.2014.102.02

19. Souty J (2013) Dynamics of patrimonialization in urban revitalization and globalization context. Notes on the Port Area of Rio de Janeiro. Revista Memória em Rede, Pelotas 3(9). ISSN 2177-4129

20. Hassan AM, Lee $H$ (2014) The paradox of the sustainable city: definitions and examples. Environ Dev Sustain. https://doi. org/10.1007/s10668-014-9604-z

21. Ahern J (2013) Urban landscape sustainability and resilience: the promise and challenges of integrating ecology with urban planning and design. Landsc Ecol 28:1203-1212. https://doi. org/10.1007/s10980-012-9799-z

22. Frantzeskaki N, Wittmayer J, Loorbach D (2014) The role of partnerships in 'realising' urban sustainability in Rotterdam's City Ports Area, The Netherlands. J Clean Prod. https://doi. org/10.1016/j.jclepro.2013.09.023

23. Anguluri $R$, Narayanan $P$ (2017) Role of green space in urban planning: outlook towards smart cities. Urban For Urban Green 25:58-65. https://doi.org/10.1016/j.ufug.2017.04.007

24. Lefebvre $H$ (1969) The right to the city. Le Droit à la ville. Documentos, São Paulo

25. IBGE Database: MANAUS. https://cidades.ibge.gov.br/brasil/am/ manaus/panorama. Accessed 2 Feb 2019

26. Lynch K (1980) The image of the city. Martins Fontes, São Paulo

27. Jacobs J (2011) Life and death of American cities. Martins Fontes, São Paulo

28. Encyclopaedia Britannica. https://www.britannica.com/. Accessed 5 Feb 2020

29. Monteiro MY (1971) Establishment of Manaus. 3rd edn. aum. Rio de Janeiro

30. Dias EM (1999) The faust illusion-Manaus 1890-1920. Editora Valer, Manaus

31. Mesquita O (2006) Manaus: history and architecture: (18521910), 3rd edn rev. Editora Valer, Manaus

32. Costa $D$ (2014) When living threatens the urban order. Workers of Manaus (1890/1915). Editora Valer and Fapeam, Manaus

33. Oliveira JA (2003). Manaus from 1920-1967. The excessive sweetness and hardness of a city. Editora Universidade Federal do Amazonas, Manaus

34. Medeiros ACC, Silva EFSA (2017) Use and occupation of urban land in the center of Manaus: the role of legislation in combating urban voids. In: PIB-SA 0046/2015. XXVII CONIC. Federal University of Amazonas, Manaus

35. Maricato E (2014) The impasse of urban politics in Brazil, 3rd edn. Vozes, Petrópolis

36. Hall P (2016) Cities of tomorrow. Translate Maria Alice Bastos, Pérola de Carvalho e Anita Guimarães, 4th edn. Perspectiva, São Paulo

37. Thi Bich Ngoc N, The Dan L (2018) Design of the landscape diversity of commercial streets in the old downtown of Ho Chi Minh City. MATEC Web of Conferences, 193, p 01017. https://doi. org/10.1051/matecconf/201819301017

38. IMPLURB Database: Only Available to visitation and local consultation (2017). http://implurb.manaus.am.gov.br/. Accessed 1 Oct 2017

39. Medeiros ACC, Fonseca RP (2017) Residential occupation of vacant lots in the central district of Manaus through modular and ephemeral housing. Dissertation, Federal University of Amazonas

40. Brazil (1967) Decree-Law No. 271 of February 28, 1967. Law on Urban Subdivision, Responsibility of the Land Granting Concession of Use and Airspace and Gives Other Measures

41. Brazil (2001) Law No. 10,257, of July 10, 2001. City Statute

42. Amazonas (2014) Complementary Law No. 002 of 16 January 2014. Law on the Urban and Environmental Master Plan of the Municipality of Manaus and provides other measures

43. Macedo J (2013) Planning a sustainable city: the making of Curitiba, Brazil. J Plan Hist. https://doi.org/10.1177/1538513213 482093

44. Silva AMC (2008) Trilogy of Urban Utopias: Urbanism, comic books and Cinema. Dissertation, Federal University of Bahia

45. Alfadala E, Furlan R (2018) Sustainable neighborhoods in the state of Qatar: Msheireb Downtown Doha. https://doi. org/10.13140/rg.2.2.34440.06401

46. Panagopoulos T, González Duque JA, Bostenaru Dan M (2016) Urban planning with respect to environmental quality and 
human well-being. Environ Pollut 208:137-144. https://doi. org/10.1016/j.envpol.2015.07.038

47. Araújo EFS (2011) The architectural and urban impacts of the PROSAMIM program on the landscape of Manaus. UFAM, Manaus

48. Meerow S, Newell JP, Stults $M$ (2016) Defining urban resilience: a review. Landsc Urban Plan 147:38-49. https://doi.org/10.1016/j. landurbplan.2015.11.011

49. Bertilsson L, Wiklund K, de Moura Tebaldi I, Rezende OM, Veról AP, Miguez MG (2018) Urban flood resilience-a multi-criteria index to integrate flood resilience into urban planning. J Hydrol. https://doi.org/10.1016/j.jhydrol.2018.06.052
50. Baró F, Palomo I, Zulian G, Vizcaino P, Haase D, Gómez-Baggethun E (2016) Mapping ecosystem service capacity, flow and demand for landscape and urban planning: a case study in the Barcelona metropolitan region. Land Use Policy 57:405-417. https://doi.org/10.1016/j.landusepol.2016.06.006

Publisher's Note Springer Nature remains neutral with regard to jurisdictional claims in published maps and institutional affiliations. 